\title{
Enhanced reduction of polymicrobial biofilms on the orthodontic brackets and enamel surface remineralization using zeolite-zinc oxide nanoparticles-based antimicrobial photodynamic therapy
}

Maryam Pourhajibagher ${ }^{1}$ and Abbas Bahador ${ }^{2,3^{*}}$

\begin{abstract}
The aim of this study was to evaluate the anti-biofilm and anti-metabolic activities of zeolite-zinc oxide nanoparticles (Zeo/ZnONPs)-based antimicrobial photodynamic therapy (aPDT) against pre-formed polymicrobial biofilms on the orthodontic brackets, as well as, assess the remineralization efficacy on polymicrobial biofilms induced enamel lesions. Following synthesis and characterization of Zeo/ZnONPs, cell cytotoxicity, hemolytic effect, and intracellular reactive oxygen species (ROS) production were determined. The anti-biofilm and anti-metabolic activities of aPDT using different concentrations of Zeo/ZnONPs were investigated. Microhardness tester and DIAGNOdent Pen were used to evaluate the changes of remineralization degree on the treated enamel slabs duration 1 and 3 months. No significant cytotoxicity and erythrocyte hemolysis were observed in treated cells with Zeo/ZnONPs. When irradiated, suggesting that the Zeo/ZnONPs were photoactivated, generating ROS and leading to reduce dose-dependently the cell viability and metabolic activity of polymicrobial biofilms. Also, the enamel surface microhardness value of exposed enamel showed a steady increase with the concentration of Zeo/ZnONPs. No statistically significant differences were shown between aPDT and sodium fluoride varnish as the control group. Overall, Zeo/ZnONPs-based aPDT with the greatest remineralization efficacy of enamel surface can be used as an anti-biofilm therapeutic method, which is involved with their potent ability to produce ROS.
\end{abstract}

Keywords: Orthodontic brackets, Remineralization, Zinc oxide, Antimicrobial photodynamic therapy, Natural zeolite

\section{Background}

Fixed orthodontic appliances may change the oral ecosystem via increasing the number of cariogenic microorganisms, accumulation of plaque, decreased plaque $\mathrm{pH}$, increasing the risk of enamel demineralization, and development of gingival inflammation [1-3].

\footnotetext{
*Correspondence: abahador@sina.tums.ac.ir

${ }^{2}$ Oral Microbiology Laboratory, Department of Microbiology, School

of Medicine, Tehran University of Medical Sciences|, Tehran, Iran

Full list of author information is available at the end of the article
}

Demineralization around the orthodontic brackets and the emergence of white spot lesions (WSLs) may lead to the development of decay in patients who do not cooperate with oral hygiene, despite modern advances in the preventive methods of dental caries $[4,5]$.

According to the literature, Streptococcus spp. have the best capacity to adhere and form biofilms on the orthodontic brackets [6]. Moreover, the amount of Lactobacillus acidophilus as the source of acid to demineralizes the enamel increases [7]. As previously reported, treatment with orthodontic appliances enhances Candida 
albicans colonization by their ability to form biofilms [8]. Although the recent use of self-ligating brackets in orthodontics has contributed to decreasing plaque accumulation, salivary calculus accumulation over the sliding clip mechanism and into the horizontal archwire slot can disrupt the function of these brackets $[9,10]$.

In recent years, antimicrobial photodynamic therapy (aPDT) has been developed as an established adjuvant therapeutic approach being readily used in dentistry to improve oral health care and control the oral cavity's microbial load [11-13]. During aPDT, a light source (such as halogen lamps, laser, or light-emitting diode) with used in dentistry to improve oral health care and control the oral cavity's microbial load specific wavelength activates some types of drugs, called photosensitizer in the presence of oxygen, producing reactive oxygen species that induce cell death $[14,15]$. As previously reported, it is far from expected that resistant bacterial strains could be expanded due to the repeated uses of aPDT due to the nonspecific nature of its underlying antimicrobial mechanism [16].

As previous studies reported zinc oxide nanoparticles ( $\mathrm{ZnONPs}$ ), belonging to the family of semiconducting metal oxide, are used as photosensitizers in aPDT [17-20]. It is reported that, by increasing the particle size of $\mathrm{ZnO}$ in the nanometer range, the surface energy increases, nanoparticles accumulate based on the Van der Waals forces and/or other interactions, and eventually leads to a decrease in the stability, mechanic strength, and hence of the $\mathrm{ZnO}$ activity and efficiency [21,22]. To improve the biostability of ZnONPs, the attachment hosts, supports, and stabilizer materials with high surface area and pore volume are used to overcome the limitations [23, 24].

Among the various supports, zeolites (Zeos) are the porous crystalline silicates with a complex crystallographic structure, as well as, high stability and surface area. They have a highly regular and open microporous structure which formed by a three-dimensional network of $\left[\mathrm{SiO}_{4}\right]^{4-}$ and $\left[\mathrm{AlO}_{4}\right]^{5-}$ tetrahedral that are connected with each other. On the other hand, Zeo could have enhanced the uptake amount of some photosensitizers by target cells [25]. In this study, ZnONPs are loaded on Zeo to realize the synergistic effect, enhance their photocatalytic activity, and prevent their agglomeration. Moreover, the Zeo crystal framework is used to improve the management of $\mathrm{ZnONPs}$, uniform distributions, and increase the antimicrobial activity of ZnONPs.

Also, according to the data obtained after a comprehensive literature review, no study exists to evaluate the anti-biofilm activities of $\mathrm{Zeo} / \mathrm{ZnONPs-based}$ aPDT. Therefore, this ex vivo study aimed to characterize and assess the anti-biofilm growth potencies and anti-metabolic activities of natural Zeo/ZnONPs-based aPDT against preformed polymicrobial biofilms on the orthodontic brackets, as well as, evaluate the remineralization efficacy of Zeo/ZnONPs-based aPDT on polymicrobial biofilms induced enamel lesions.

\section{Results}

\section{Confirmation of Zeo/ZnONPs synthesis}

Figures 1a demonstrate granular shapes of Zeo/ZnONPs which are confirmed by FESEM, indicating the presence of ZnONPs on the smooth surface and cubic structure of Zeo. It can be clearly seen in Fig. $1 \mathrm{~b}$ that the particle size of Zeo/ZnONPs is in the range of $34.03-110.1 \mathrm{~nm}$ and an average diameter of $52.85 \mathrm{~nm}$.

The presence of ZnONPs attached in Zeo is shown in the TEM image of Zeo/ZnONPs (Fig. 2).

The UV-visible spectrum of Zeo/ZnONPs aqueous solution is presented in Fig. 3. As shown, the absorption spectrum of $\mathrm{Zeo} / \mathrm{ZnONPs}$ is broadband with a maximum absorbance peak at a wavelength $\sim 392 \mathrm{~nm}$.

According to the results in Fig. 4, the mean of zeta potential distribution of Zeo/ZnONPs was $-15.9 \mathrm{mV}$ (a). The electrophoretic mobility distribution, frequency shift, and effective voltage of Zeo/ZnONPs were - 1.249 $\mu \mathrm{mcm} / \mathrm{Vs}(\mathrm{b}), 283 \mathrm{~Hz}(\mathrm{c})$, and $140 \mathrm{v}(\mathrm{d})$, respectively.

The elemental mapping of $\mathrm{Zeo} / \mathrm{ZnONPs}$ observed in Fig. 5 shows a homogeneous distribution of the mentioned elements, as well as, percentage of each element over the entire nano-photosensitizer.

\section{Hemolysis effect of Zeo/ZnONPs}

The percentage of hemolytic erythrocytes was assessed to determine whether the synthesized $\mathrm{Zeo} / \mathrm{ZnONPs}$ destroyed the membrane of RBCs, which can lead to the release of hemoglobin into the plasma by changing membrane integrity and pore formation on RBCs membrane. This evaluation is crucial, as without it the use of Zeo/ ZnONPs may result in dangerous pathological conditions. In the current study, the hemolytic activity of Zeo/ $\mathrm{ZnONPs}$ at the concentrations of $0.5,1$, and $2 \times 10^{-4} \mathrm{~g} / \mathrm{L}$ exhibited that there was no related destruction of RBCs (Fig. 6), suggesting their great hemocompatibility which was similar to the negative control (PBS).

\section{MTT and SRB colorimetric assays for cytotoxicity screening} The cytotoxic effects of Zeo/ZnONPs based on MTT assay on the viability of $\mathrm{HuGu}$ cells are presented as percent cell viability in Fig. 7. Treatment with different concentrations of Zeo/ZnONPs did not affect cell viability in $\mathrm{HuGu}$ cells, compared with the control group $(P>0.05)$. Also, the results for MTT and SRB showed a similar pattern where there was no considerable decrease in cell viability with increasing Zeo/ZnONPs 


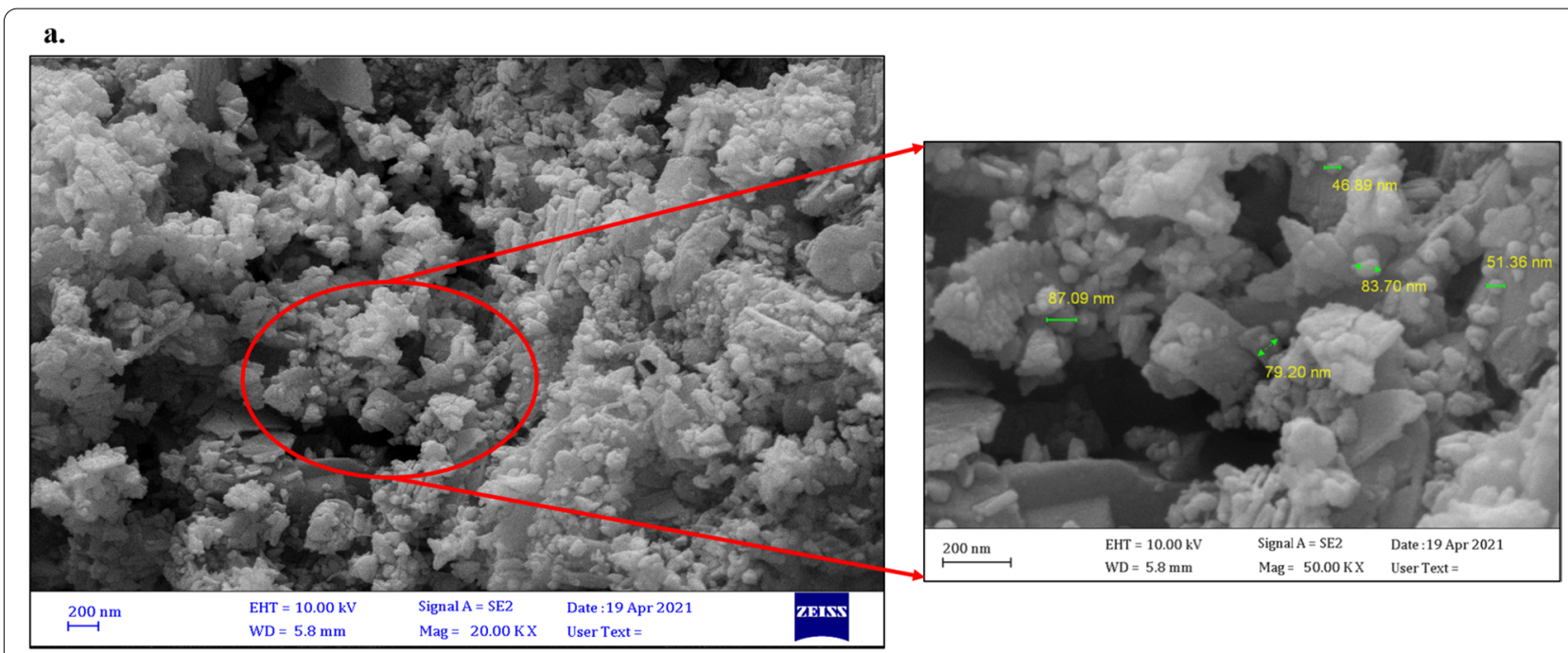

b.

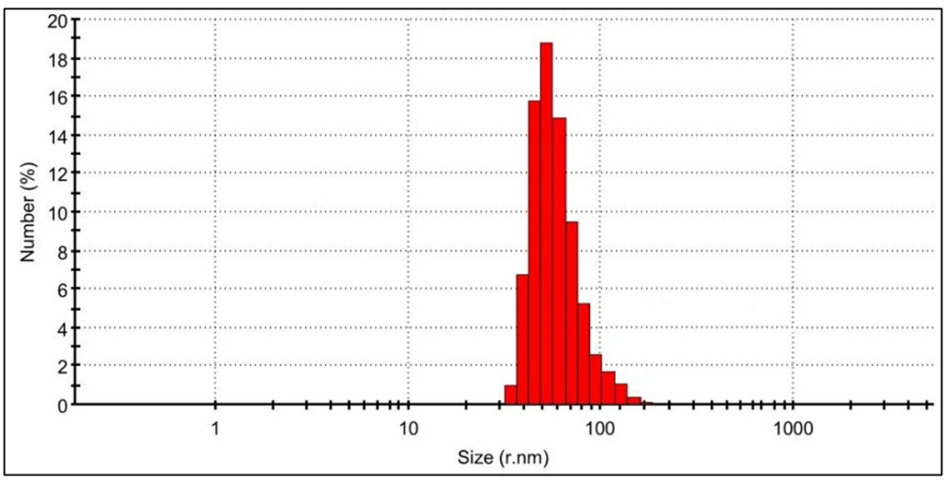

Fig. 1 a FESEM image of Zeo/ZnONPs (Scale bar $=200 \mathrm{~nm} ; \mathrm{Mag}=20.00 \mathrm{KX}$ ), b Particle size of Zeo/ZnONPs

concentration $(\mathrm{P}>0.05)$. As shown in Fig. 7, the numbers of treated $\mathrm{HuGu}$ cells with $2 \times 10^{-4} \mathrm{~g} / \mathrm{L} \mathrm{Zeo/}$ $\mathrm{ZnONPs}$ were dropped slightly to 19.4 and $18.7 \%$ when compared to the controls in MTT and SRB assays, respectively $(P>0.05)$. Accordingly, the results of the MTT-based cytotoxicity assay were in agreement with the cytotoxic assay based on SRB.

\section{Intracellular ROS production}

No significant increase in the DCFH-DA fluorescence was observed in polymicrobial suspension subjected to $\mathrm{Zeo} / \mathrm{ZnONPs}$ alone and $\mathrm{CHX}(\mathrm{P}>0.05$; Fig. 8). A remarkable increase in the intracellular ROS generation was evident when the polymicrobial suspension was subjected to $\mathrm{Zeo} / \mathrm{ZnONPs}$-mediated aPDT, which was dose-dependent $(P<0.05)$. Accordingly, $2 \times 10^{-4} \mathrm{~g} / \mathrm{L}$ of $\mathrm{Zeo} / \mathrm{ZnONPs}$ produced 1.87 -fold higher ROS in polymicrobial suspension compared to the control group $(\mathrm{P}<0.05)$. Also, the results revealed an increase (1.15-fold) in polymicrobial suspension exposed to blue laser alone.

\section{Anti-biofilm capability}

The concentration-dependent anti-biofilm activity was observed in Zeo/ZnONPs (Fig. 9). However, greater anti-biofilm potency was observed by combining Zeo/ $\mathrm{ZnONPs}$ and blue laser light. When combined, 0.5, 1, and $2 \times 10^{-4} \mathrm{~g} / \mathrm{L}$ concentrations of Zeo/ZnONPs represent anti-biofilm values of 4.6, 6.2, and 9.2 $\log _{10} \mathrm{CFU} /$ $\mathrm{mL}$, respectively. Anti-biofilm activities obtained from both aPDT and $0.2 \%$ CHX groups were similar $(P>0.05)$. In contrast, no significant inhibition was achieved from the blue laser alone.

Interestingly, SEM images in Fig. 10 confirm the results obtained from $\log _{10}$ CFUs/mL.

\section{Anti-metabolic activity}

The anti-metabolic activity of $\mathrm{Zeo} / \mathrm{ZnONPs}$ at various concentrations in the combination with blue laser light 


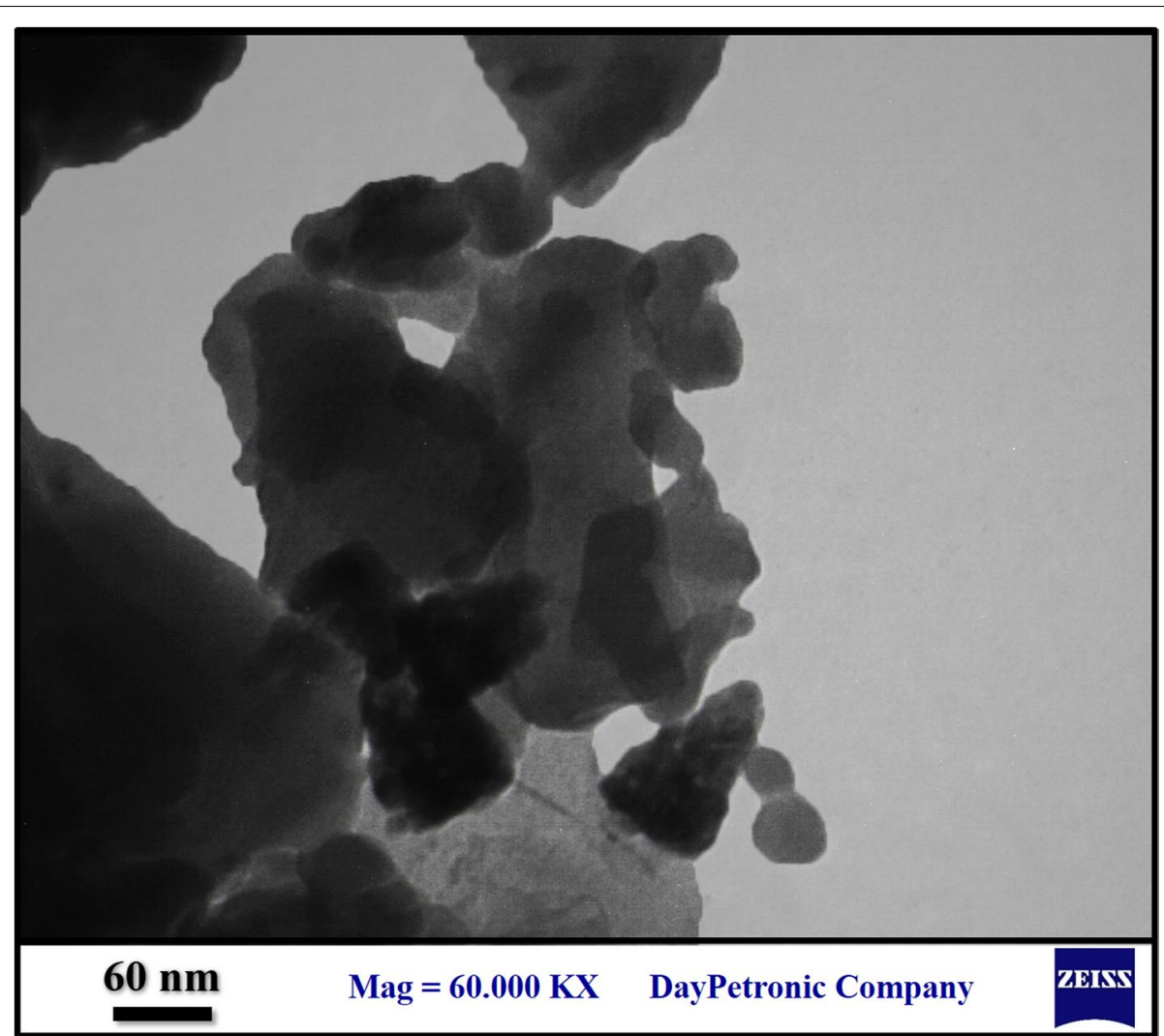

Fig. 2 TEM image of Zeo/ZnONPs (Scale bar $=60 \mathrm{~nm}$ )

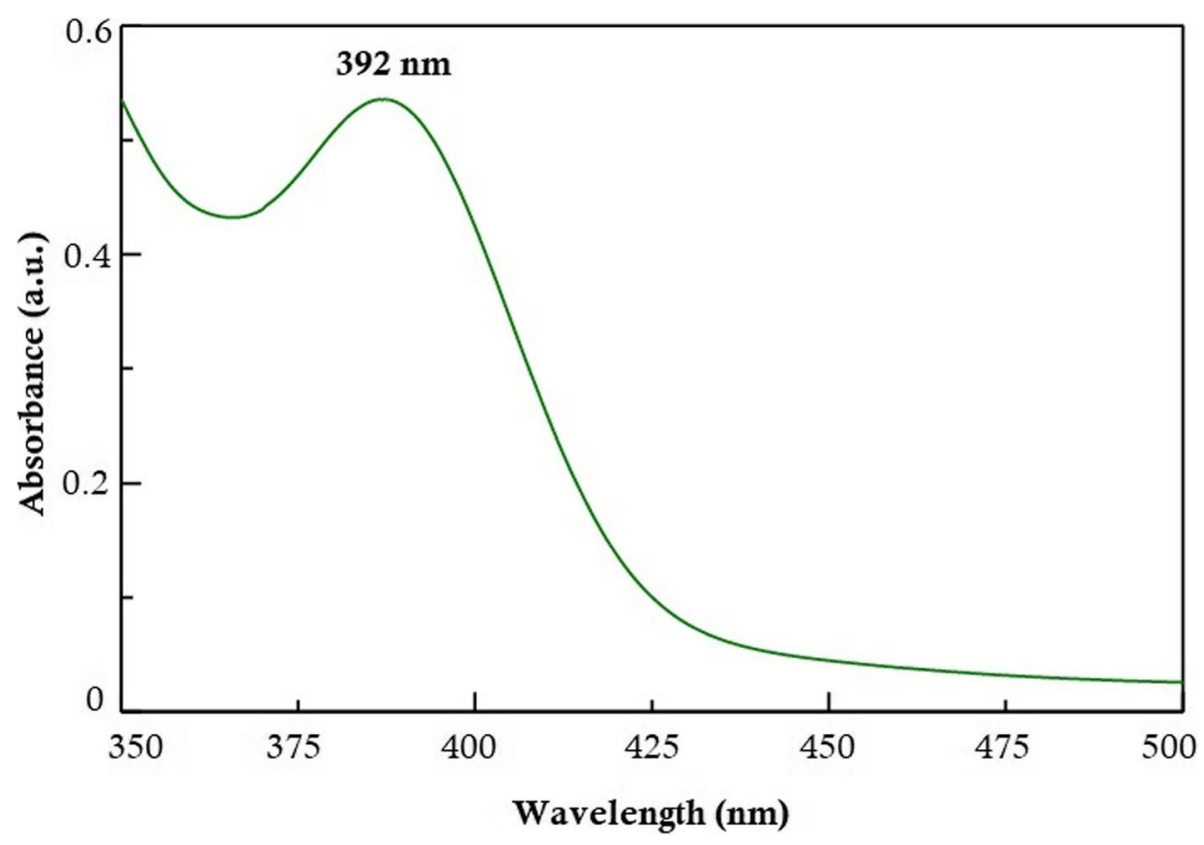

Fig. 3 UV-visible spectrum of Zeo/ZnONPs 


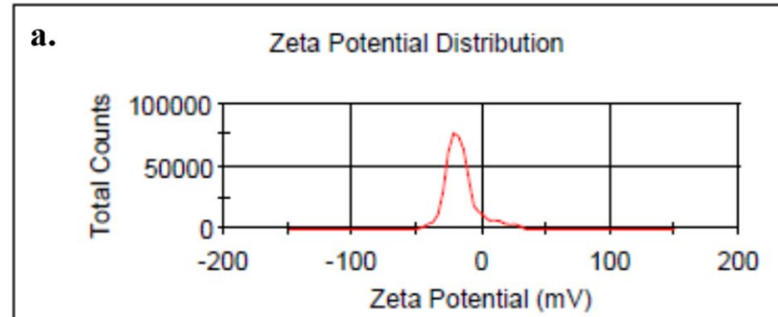

b.
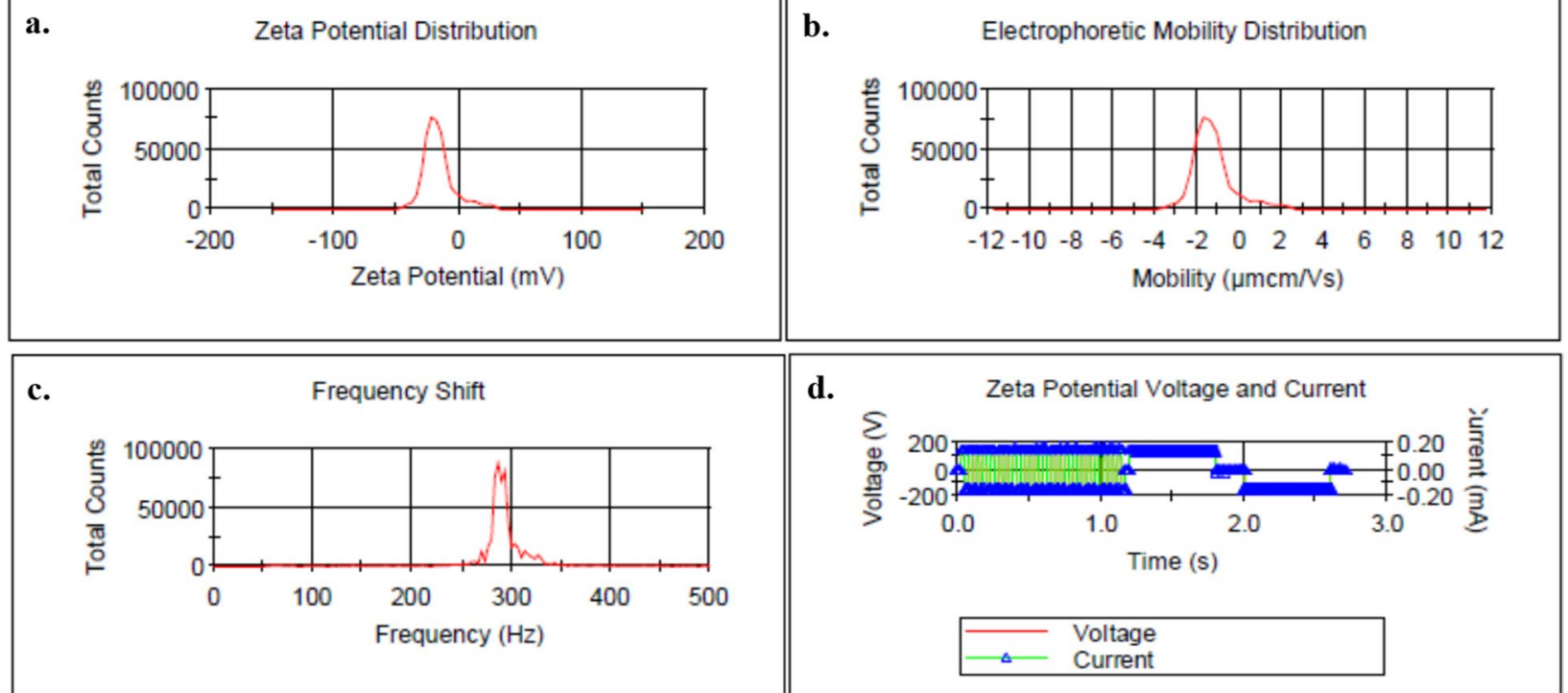

Fig. 4 Characterization of Zeo/ZnONPs; a Zeta potential distribution, b Electrophoretic mobility distribution, c Frequency shift, d Effective voltage
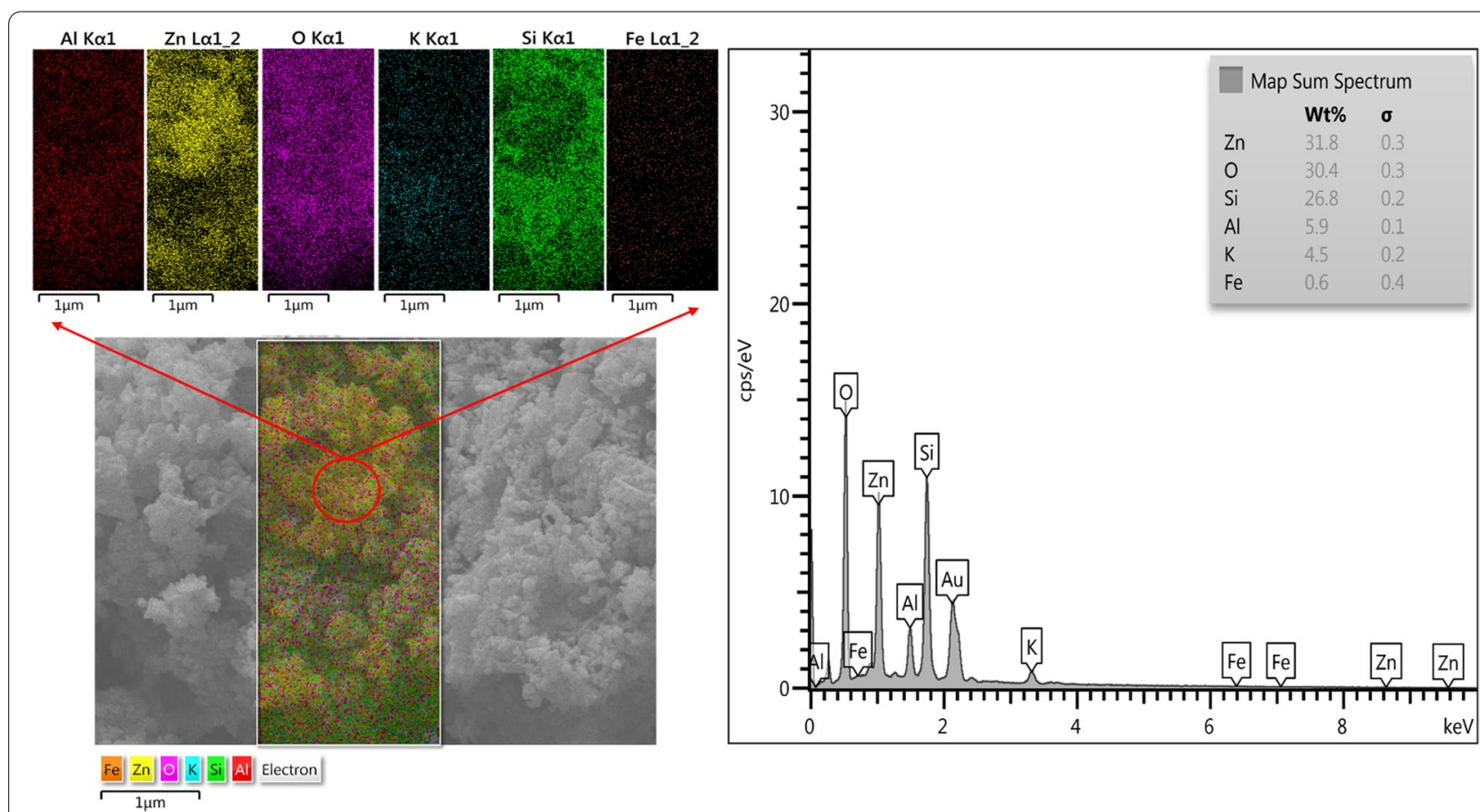

Fig. 5 Elemental mapping of Zeo/ZnONPs

was evaluated (Fig. 11). According to the XTT colorimetric assay, aPDT using $2 \times 10^{-4} \mathrm{~g} / \mathrm{L}$ of Zeo/ZnONPs showed significantly greater anti-metabolic activity as compared to the other group with an inhibition percentage of $78.6 \%(P<0.05)$. No considerable difference was observed between $2 \times 10^{-4} \mathrm{~g} / \mathrm{L}$ of Zeo/ZnONPsmedaited aPDT and $0.2 \%$ CHX $(P>0.05)$. As shown in Fig. 11 , after treatment with $0.5,1$, and $2 \times 10^{-4} \mathrm{~g} / \mathrm{L}$ of $\mathrm{Zeo} / \mathrm{ZnONPs}$, the metabolic activity of polymicrobial biofilms decreased by $15.1,21.7$, and $29.4 \%$, respectively. There was no significant effect of anti-metabolic 


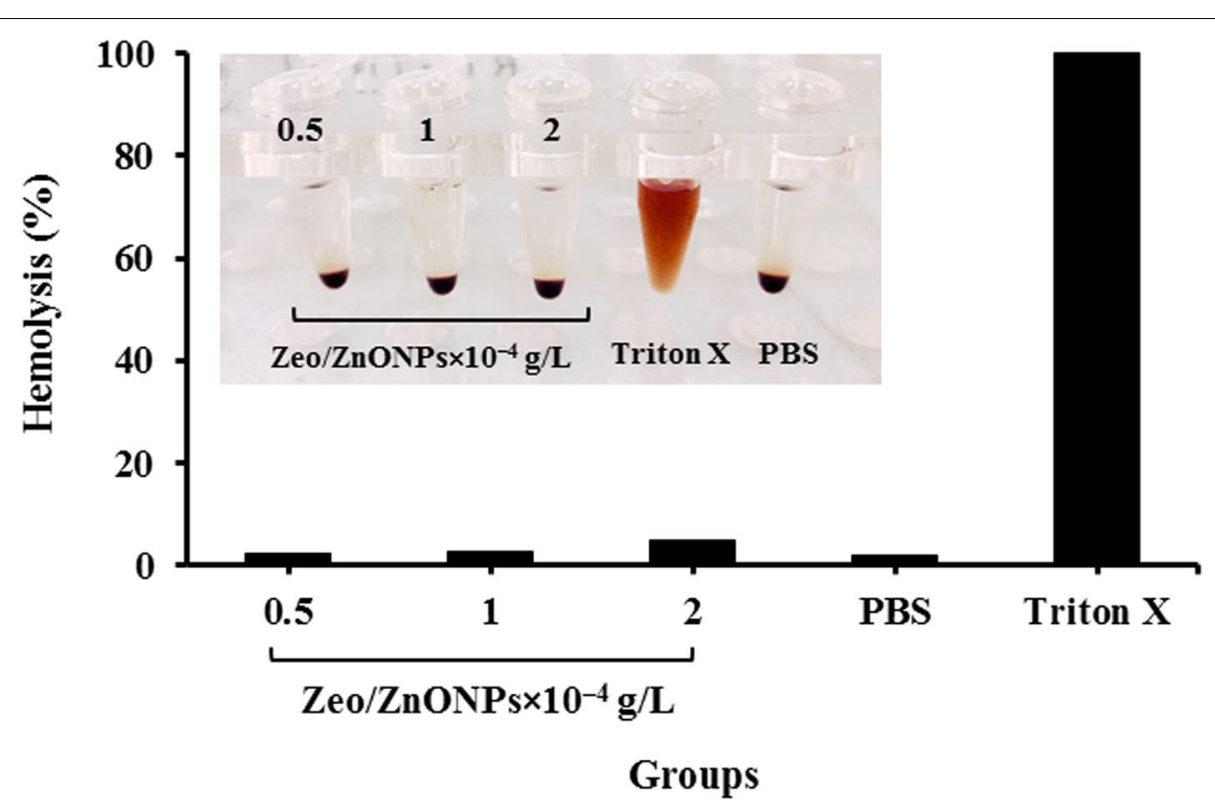

Fig. 6 Hemolytic effect of Zeo/ZnONPs

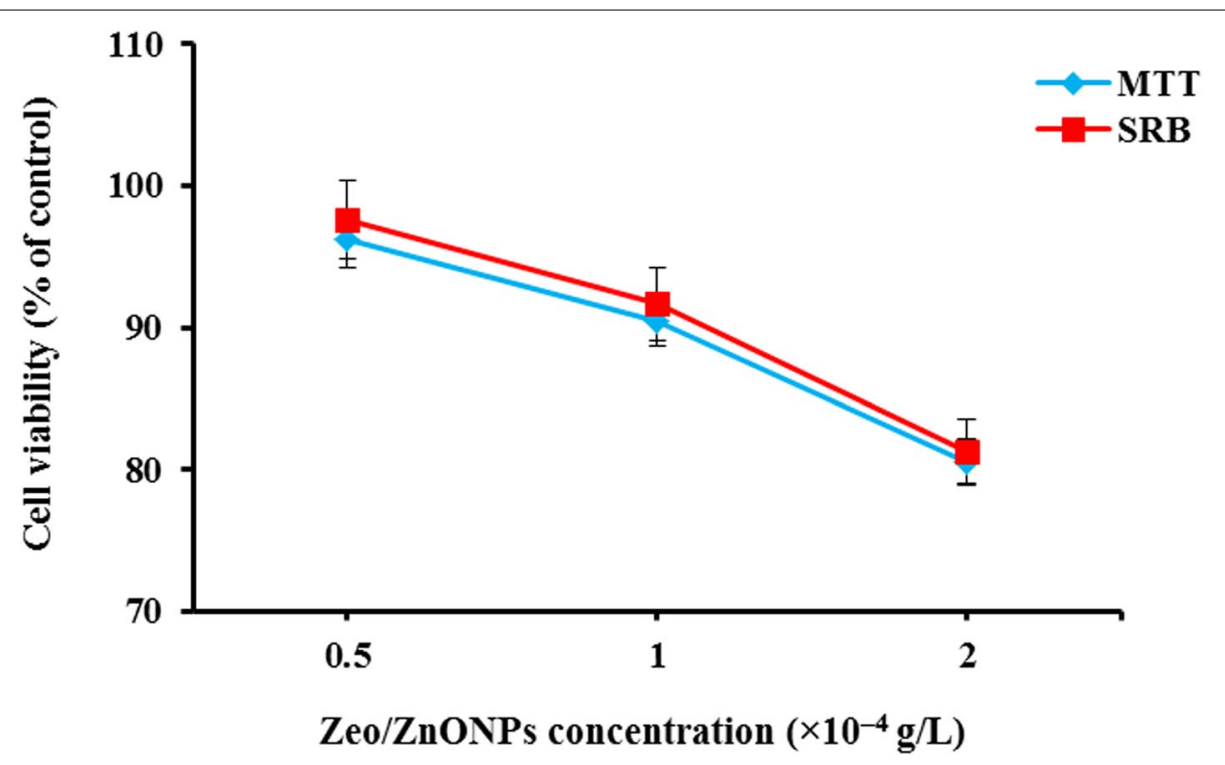

Fig. 7 Cytotoxic effects of Zeo/ZnONPs on cell viability of HuGu cells

activity observed of the blue laser light on polymicrobial biofilms $(P>0.05)$.

\section{Evaluation of enamel remineralization}

The results of ESM were shown in Table 1. There was no significant difference between the value of artificial saliva as a control group and that after demineralization $(P>0.05)$. ESM of the NaF varnish group as a treatment control group increased significantly compared with the artificial saliva group $(P<0.05)$. For aPDT group based on $2 \times 10^{-4} \mathrm{~g} / \mathrm{L}$ of Zeo/ZnONPs, the value of ESM at all time points was consistent with that of $\mathrm{NaF}$ varnish group and there was no statistical difference between these two groups $(P>0.05)$. ESM of blue laser and Zeo/ZnONPs groups increased insignificantly comparing with the NaF varnish group $(\mathrm{P}>0.05)$, and there was no statistical difference between those two groups (blue laser and Zeo/ ZnONPs groups; $\mathrm{P}>0.05$ ). 


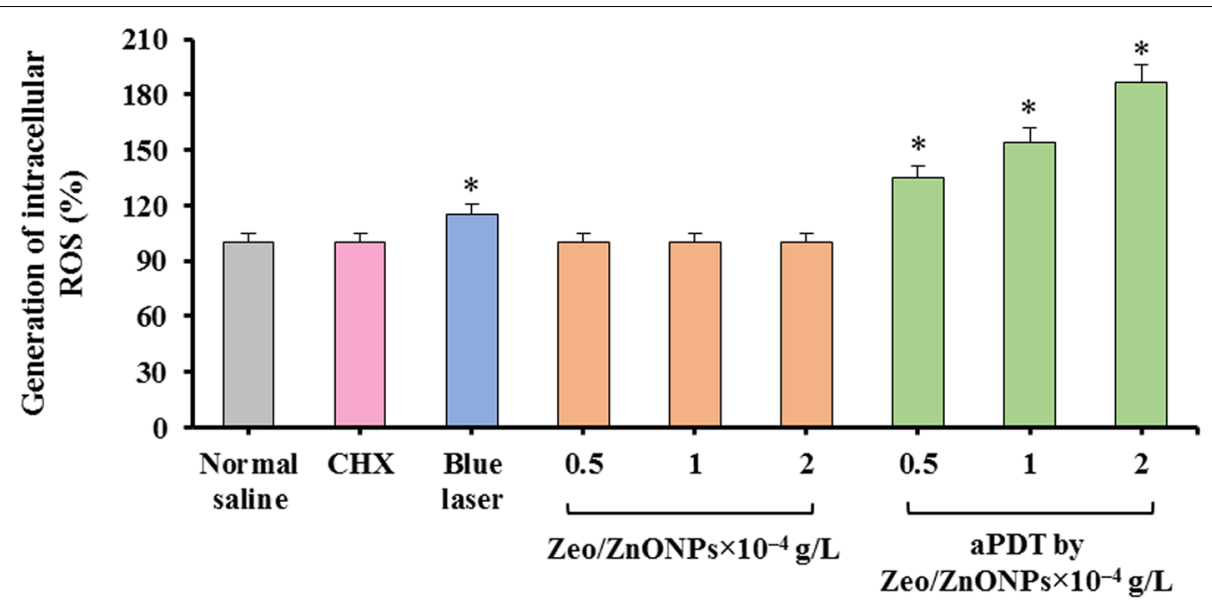

Gropus

Fig. 8 Intracellular ROS production in polymicrobial suspension following different treatments

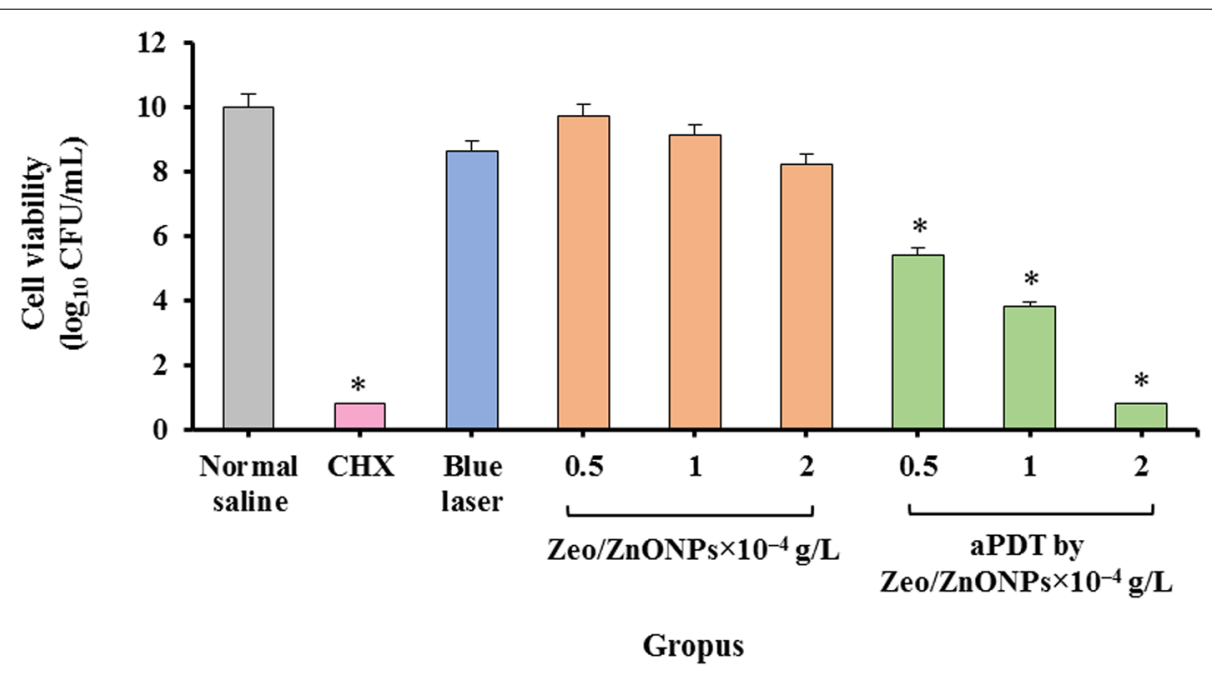

Fig. 9 Cell viability of polymicrobial suspension following different treatments

DIAGNOdent Pen results were shown in Table 2. No statistical difference was found among the readings of control, blue laser, and $\mathrm{Zeo} / \mathrm{ZnONPs}$ groups and with that after demineralization $(P>0.05)$. Readings of $\mathrm{NaF}$ varnish and aPDT groups were at the same level $(\mathrm{P}>0.05)$, which were significantly reduced comparing with the three above-mentioned groups $(P<0.05)$. The reading of aPDT group based on $2 \times 10^{-4} \mathrm{~g} / \mathrm{L}$ of $\mathrm{Zeo} /$ ZnONPs was the lowest, which was statistically different from all of the above-mentioned groups $(\mathrm{P}<0.05)$, except the $\mathrm{NaF}$ varnish group.

\section{Discussion}

Dental plaque accumulation and inadequate personal oral hygiene are the severe challenges for maintaining oral health in orthodontic patients [26]. Reduction of bacterial colonization and removal of dental biofilms as one of the most important etiologic parameters for oral pathological conditions are performed by various techniques, but with limited success [27, 28].

Recently, aPDT has been introduced as an alternative therapy for preventing and treating dental caries via control the formation of the microbial biofilm and controlling the incidence of microbial pathogens without the development of resistance [29-31]. Several variables such 

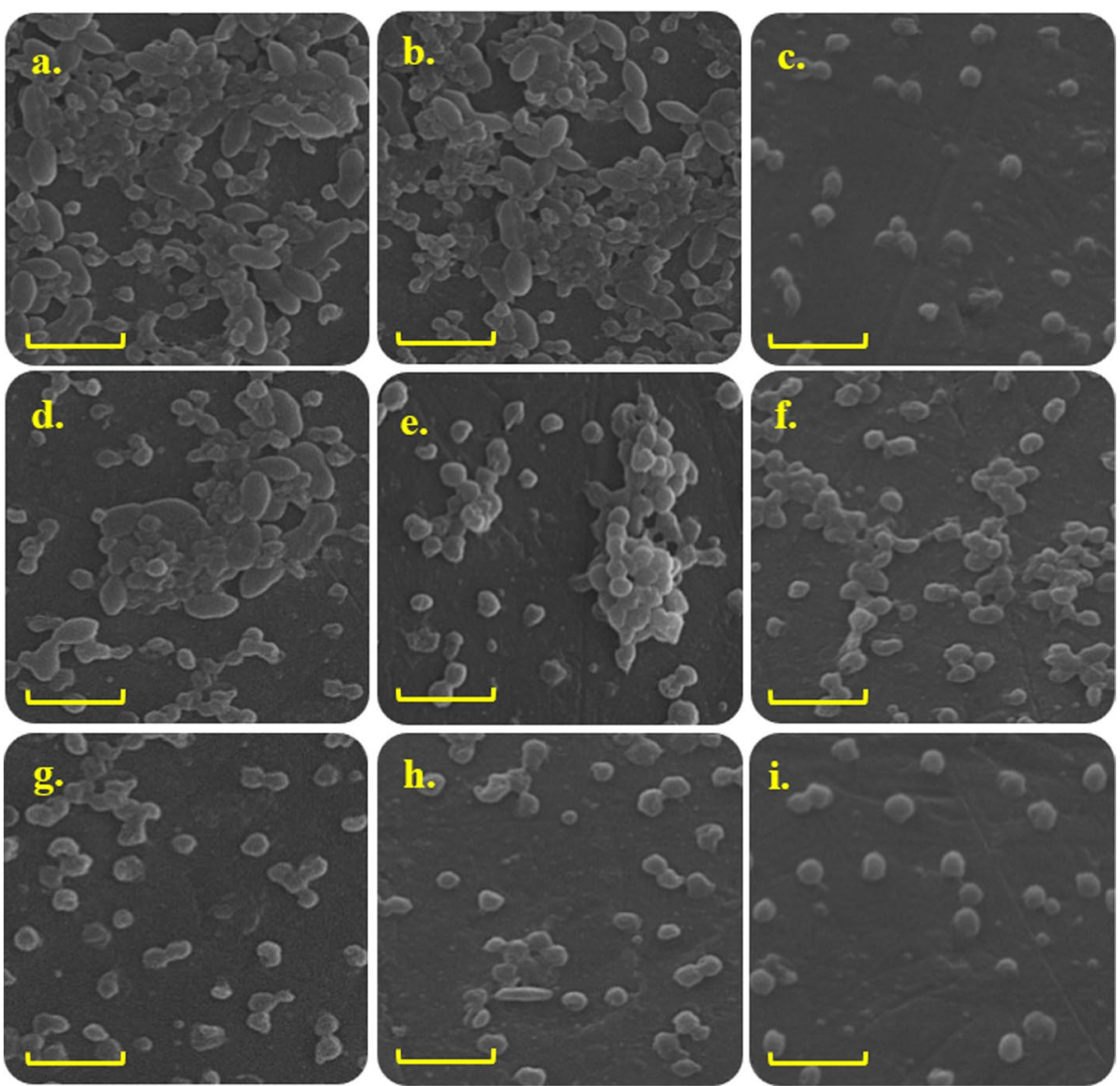

Fig. 10 SEM images of polymicrobial biofilms viability following different treatments (Scale bar $=5 \mu \mathrm{m}, \mathrm{Mag}=20.00 \mathrm{KX}$ ). a) Negative control: Normal saline, b) Blue laser, c) Positive control:0.2\% CHX, d) $0.5 \times 10^{-4} \mathrm{~g} / \mathrm{L}$ of Zeo/ZnONPs, e) $1 \times 10^{-4} \mathrm{~g} / \mathrm{L}$ of Zeo/ZnONPs, f) $2 \times 10^{-4} \mathrm{~g} / \mathrm{L}$ of Zeo/ ZnONPs, g) aPDT using $0.5 \times 10^{-4} \mathrm{~g} / \mathrm{L}$ of Zeo/ZnONPs, h) aPDT using $1 \times 10^{-4} \mathrm{~g} / \mathrm{L}$ of Zeo/ZnONPs, i) aPDT using $2 \times 10^{-4} \mathrm{~g} / \mathrm{L}$ of Zeo/ZnONPs

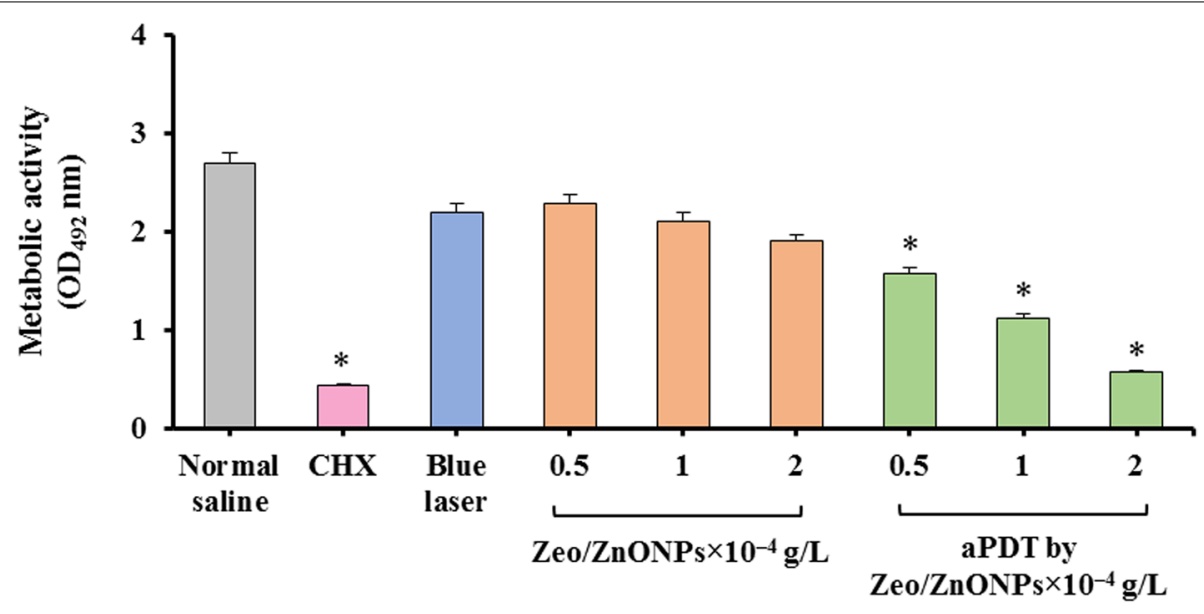

Gropus

Fig. 11 Metabolic activity of polymicrobial suspension following different treatments 
Table 1 Mean of descriptive statistics of enamel microhardness values $(E M H)$ in different conditions.

\begin{tabular}{|c|c|c|c|c|}
\hline \multirow[t]{2}{*}{ Treatment } & \multirow[t]{2}{*}{ Intact } & \multirow[t]{2}{*}{ Demineralized $\left(t_{0}\right)$} & \multicolumn{2}{|c|}{$\begin{array}{l}\text { Demineralized and } \\
\text { remineralized }\end{array}$} \\
\hline & & & $t_{2}$ & $t_{1}$ \\
\hline $\mathrm{NaF}$ & 3.78 & 2.25 & 3.09 & 2.57 \\
\hline$S D^{\mathrm{a}}$ & 0.19 & 0.28 & 0.17 & 0.22 \\
\hline $\operatorname{Min}^{b}$ & 3.48 & 2.02 & 2.72 & 2.44 \\
\hline $\operatorname{Max}$ & 4.15 & 2.33 & 3.31 & 2.76 \\
\hline $0.5 \times 10^{-4} \mathrm{~g} / \mathrm{L}$ of Zeo $/ \mathrm{ZnONPs}$ & 3.69 & 2.07 & 2.18 & 2.12 \\
\hline SD & 0.22 & 0.19 & 0.22 & 0.33 \\
\hline Min & 3.31 & 1.86 & 2.04 & 2.01 \\
\hline Max & 4.12 & 2.33 & 2.51 & 2.49 \\
\hline $1 \times 10^{-4} \mathrm{~g} / \mathrm{L}$ of Zeo/ZnONPs & 3.64 & 2.01 & 2.21 & 2.09 \\
\hline SD & 0.20 & 0.16 & 0.31 & 0.21 \\
\hline Min & 3.55 & 1.84 & 2.05 & 1.82 \\
\hline Max & 4.01 & 2.27 & 2.28 & 2.16 \\
\hline $2 \times 10^{-4} \mathrm{~g} / \mathrm{L}$ of Zeo/ZnONPs & 3.72 & 2.18 & 2.43 & 2.23 \\
\hline SD & 0.18 & 0.19 & 0.18 & 0.25 \\
\hline Min & 3.67 & 2.01 & 2.25 & 2.12 \\
\hline Max & 3.99 & 2.64 & 2.78 & 2.61 \\
\hline Blue laser & 3.82 & 2.28 & 2.39 & 2.35 \\
\hline SD & 0.19 & 0.25 & 0.15 & 0.24 \\
\hline Min & 3.41 & 2.11 & 2.23 & 2.11 \\
\hline Max & 3.89 & 2.40 & 2.48 & 2.52 \\
\hline $0.5 \times 10^{-4} \mathrm{~g} / \mathrm{L}$ of Zeo $/ \mathrm{ZnONPs}+$ Blue laser & 3.73 & 2.11 & 2.45 & 2.22 \\
\hline SD & 0.19 & 0.27 & 0.22 & 0.31 \\
\hline Min & 3.61 & 2.01 & 2.34 & 2.14 \\
\hline Max & 3.86 & 2.25 & 2.91 & 2.64 \\
\hline $1 \times 10^{-4} \mathrm{~g} / \mathrm{L}$ of Zeo/ZnONPs + Blue laser & 3.78 & 2.25 & 2.75 & 2.43 \\
\hline SD & 0.26 & 0.21 & 0.29 & 0.27 \\
\hline Min & 3.68 & 2.16 & 2.27 & 2.25 \\
\hline Max & 4.02 & 2.47 & 3.04 & 2.73 \\
\hline $2 \times 10^{-4} \mathrm{~g} / \mathrm{L}$ of Zeo/ZnONPs + Blue laser & 3.77 & 2.22 & 3.42 & 2.69 \\
\hline SD & 0.26 & 0.27 & 0.27 & 0.25 \\
\hline Min & 3.31 & 1.87 & 2.68 & 2.33 \\
\hline Max & 3.82 & 2.56 & 3.58 & 3.11 \\
\hline Artificial saliva & 3.88 & 2.32 & 2.30 & 2.36 \\
\hline SD & 0.19 & 0.43 & 0.21 & 0.19 \\
\hline Min & 3.71 & 2.02 & 2.09 & 2.12 \\
\hline Max & 3.93 & 2.54 & 2.42 & 2.54 \\
\hline
\end{tabular}

a Standard deviation

b Minimum

c Maximum

as the type and concentration of photosensitizers, light sources, irradiation parameters, and physiologic condition of the microorganisms studied must be considered for the effectiveness of aPDT [32].

Many in vitro and in vivo studies present high efficiency of aPDT against microorganisms involved in dental caries [13, 33-37]. The results of Alqerban [38] study showed that not only aPDT with Riboflavin and Rose Bengal can be used for bonding orthodontic brackets to the tooth surface but also revealed the substantial antibacterial properties against $S$. mutans. Hugo Panhóca et al. [39] reported aPDT with Curcumin reduces the number of living cells of $S$. mutans in a biofilm model created on the surface of metallic orthodontic accessories. 
Table 2 Mean of DIAGNOdent Pen readings of the lesions before and after remineralization

\begin{tabular}{|c|c|c|c|c|}
\hline \multirow[t]{2}{*}{ Treatment } & \multirow[t]{2}{*}{ Intact } & \multirow[t]{2}{*}{ Demineralized $\left(t_{0}\right)$} & \multicolumn{2}{|c|}{$\begin{array}{l}\text { Demineralized and } \\
\text { remineralized }\end{array}$} \\
\hline & & & $t_{1}$ & $t_{2}$ \\
\hline $\mathrm{NaF}$ & 3.78 & 9.61 & 8.37 & 9.18 \\
\hline$S D^{\mathrm{a}}$ & 0.19 & 0.71 & 0.81 & 0.78 \\
\hline $\operatorname{Min}^{b}$ & 3.48 & 9.12 & 8.21 & 8.91 \\
\hline $\operatorname{Max}$ & 4.15 & 9.98 & 8.83 & 9.52 \\
\hline $0.5 \times 10^{-4} \mathrm{~g} / \mathrm{L}$ of Zeo $/ \mathrm{ZnONPs}$ & 3.69 & 9.77 & 9.53 & 9.67 \\
\hline SD & 0.22 & 0.91 & 0.61 & 0.68 \\
\hline Min & 3.31 & 9.57 & 9.35 & 8.46 \\
\hline Max & 4.12 & 9.89 & 9.87 & 9.81 \\
\hline $1 \times 10^{-4} \mathrm{~g} / \mathrm{L}$ of Zeo/ZnONPs & 3.64 & 9.83 & 9.29 & 9.64 \\
\hline SD & 0.20 & 0.71 & 0.92 & 0.86 \\
\hline Min & 3.55 & 8.33 & 8.45 & 9.33 \\
\hline Max & 4.01 & 9.96 & 9.37 & 9.84 \\
\hline $2 \times 10^{-4} \mathrm{~g} / \mathrm{L}$ of Zeo/ZnONPs & 3.72 & 9.67 & 8.96 & 9.41 \\
\hline SD & 0.18 & 0.84 & 0.61 & 0.71 \\
\hline Min & 3.67 & 8.73 & 8.45 & 8.83 \\
\hline Max & 3.99 & 9.66 & 9.17 & 9.60 \\
\hline Blue laser & 3.82 & 9.51 & 8.91 & 9.26 \\
\hline SD & 0.19 & 0.58 & 0.82 & 0.65 \\
\hline Min & 3.41 & 9.45 & 8.71 & 9.33 \\
\hline Max & 3.89 & 9.84 & 9.32 & 9.78 \\
\hline $0.5 \times 10^{-4} \mathrm{~g} / \mathrm{L}$ of Zeo $/ \mathrm{ZnONPs}+$ Blue laser & 3.73 & 9.69 & 9.17 & 9.41 \\
\hline SD & 0.19 & 0.73 & 0.65 & 0.79 \\
\hline Min & 3.61 & 9.46 & 9.01 & 9.13 \\
\hline Max & 3.86 & 9.88 & 9.41 & 9.88 \\
\hline $1 \times 10^{-4} \mathrm{~g} / \mathrm{L}$ of Zeo/ZnONPs + Blue laser & 3.78 & 9.60 & 8.33 & 8.97 \\
\hline SD & 0.26 & 0.81 & 0.61 & 0.76 \\
\hline Min & 3.68 & 8.86 & 8.04 & 8.72 \\
\hline Max & 4.02 & 9.79 & 8.81 & 9.17 \\
\hline $2 \times 10^{-4} \mathrm{~g} / \mathrm{L}$ of Zeo/ZnONPs + Blue laser & 3.77 & 9.58 & 7.49 & 7.81 \\
\hline SD & 0.26 & 0.71 & 0.69 & 0.81 \\
\hline Min & 3.31 & 9.21 & 7.25 & 7.31 \\
\hline Max & 3.82 & 9.87 & 7.84 & 8.97 \\
\hline Artificial saliva & 3.88 & 9.46 & 9.48 & 9.34 \\
\hline SD & 0.19 & 0.72 & 0.61 & 0.53 \\
\hline Min & 3.71 & 9.33 & 9.32 & 9.55 \\
\hline Max & 3.93 & 9.84 & 9.91 & 9.79 \\
\hline
\end{tabular}

a Standard deviation

b Minimum

c Maximum

The results of previous studies showed that ZnONPs are the most promising next-generation photosensitizer for PDT due to their specific phototoxic effect on tumor areas [40-43]. According to Pourhajibgher et al. photo-activated Curcumin doped ZnONPs can use as an orthodontic adhesive additive to control the cariogenic multispecies biofilm, and also reduce their metabolic activity [7].

The biocidal cations of ZnONPs have been hosted on the surfaces and in the cavities of Zeo via ion exchange and can become an efficient nano-photosensitizer in aPDT process. On the other hand, Zeo as stable carriers with high chemical inertness and null toxicity could be 
increasing the efficacy of photosensitizer via protecting it from oxidation, increasing the permeability of the photosensitizer through the cell membrane, increasing the concentration of photosensitizer molecules in the target cells, and increasing the lifetime of photosensitizer release through a sustained process [44-47].

The possible risks of nano-photosensitizer to human health have raised concerns. These concerns underline the need and importance of assessing their cytotoxicity. In a work reported by Wang et al. [48] the cytotoxic effects of ZnONPs at concentrations of 10, 15, 30, and $100 \mu \mathrm{g} / \mathrm{mL}$ was investigated on different cell types such as human keratinocyte cells ( $\mathrm{HaCaT})$, human gingival fibroblast (HGF-1), and human gingival squamous carcinoma cell line (Ca9-22). Their results showed that ZnONPs were less toxic to normal $\mathrm{HaCaT}$ and HGF-1 cells, but showed severe toxicity to Ca9-22 cells at concentrations more than $30 \mu \mathrm{g} / \mathrm{mL}$. Seker et al. [49] and Vergara-Llanos et al. [50] reported ZnONPs exhibited cytotoxic effect at doses of $50-100 \mu \mathrm{g} / \mathrm{mL}$. Since there has been no report so far of using SRB dye in testing cytotoxicity of photosensitizers, and also considering advantages of the SRB assay such as safety and high stability of staining, in this study, the cell-killing effect of Zeo/ZnONPs as the model photosensitizer at the different concentrations was tested on $\mathrm{HuGu}$ cells. Zeo/ZnONPs at $0.5 \times 10^{-4} \mathrm{~g} / \mathrm{L}$ concentration had very low cytotoxicity; 3.8 and $2.4 \%$ of $\mathrm{HuGu}$ cells are viable following MTT- and SRB-based cytotoxicity assay, respectively. In recent years, the MTT assay has been the most widely used; however, it still has a few disadvantages. For example, the amount of MTT is not linear with cell concentration at high cell number, cell lines differ in their activity to reduce the MTT dye and the assay has large inter-assay and intra-assay variations under several conditions. Some MTT reagents also are suspected of causing genetic defects. Although there has been no report concerning physical hazards in using MTT reagents, the handling storage, and disposal of MTT reagents pose safety and environmental concerns. Thus, MTT waste must be appropriately eliminated after testing. Recently, the SRB protein staining was described as an alternative approach. The SRB assay appeared to be more sensitive than the MTT assay, with higher reproducibility and better linearity with cell concentration. In contrast to the MTT assay, SRB staining is stable and plates can be stored up to several months. SRB assay has the advantage of avoidance of handling bio-hazard compounds [51]. According to the excellent agreement was noted for the evaluation of Zeo/ZnONPs cytotoxicity and also regarding advantages of the SRB assay, this method can be used for cytotoxic screening of Zeo/ZnONPs.

Also, after a $24 \mathrm{~h}$ incubation period, 19.4 and $18.7 \%$ of $\mathrm{HuGu}$ cells were viable at the highest concentration of
Zeo/ZnONPs $\left(2 \times 10^{-4} \mathrm{~g} / \mathrm{L}\right)$ following MTT and SRB assay, respectively. As the results displayed the cytotoxicity of $\mathrm{Zeo} / \mathrm{ZnONPs}$ was dependent on concentration. In this study, the hemolytic effect of Zeo/ZnONPs on erythrocytes was assessed and its biocompatibility at the different concentrations was revealed. Babu et al. [52] explored the hemolytic effect of ZnONPs was increased with increasing concentration from 25 to $800 \mu \mathrm{g} / \mathrm{mL}$ in a time-dependent manner. Besides, the data from Ulyanova et al. [53] showed that with a decrease in the concentration of nano-zeo to $1 \mathrm{mg} / \mathrm{mL}$, there is a tendency for the hemolytic activity of the samples to decrease. Therefore, the results obtained from this study are consistent with the results of previous studies.

There are no studies in the literature on using Zeo/ ZnONPs- mediated aPDT for the inhibition of polymicrobial biofilms growth in patients undergoing orthodontic treatment. Herein, a significant decrease on the viability of microorganisms was observed when biofilms were exposed to aPDT. The present study showed an interesting result with $2 \times 10^{-4} \mathrm{~g} / \mathrm{L}$ of $\mathrm{Zeo} / \mathrm{ZnONPs}$ mediated aPDT, degradation 92 and $78.6 \%$ of biofilms, and metabolic activity of polymicrobial biofilms, respectively. In addition, no remarkable difference in the number of $\log _{10} \mathrm{CFU} / \mathrm{mL}$ was observed between Zeo/ ZnONPs- mediated aPDT $\left(2 \times 10^{-4} \mathrm{~g} / \mathrm{L}\right)$ and CHX.

Following light irradiation, the photosensitizer in its ground singlet state excited and reacts with oxygen to produce ROS. These ROS can be classified into those produced by Type I photochemical mechanism: free radicals such as superoxide radical anion $\left(\mathrm{O}^{2}{ }^{-}\right)$and hydroxyl radicals $\left(\mathrm{HO}^{*}\right)$ and those produced by Type II photochemical mechanism: singlet oxygen $\left({ }^{1} \mathrm{O}_{2}\right)$. They all have damage effects on biomolecules and kill the target cells, resulting in membrane destructive process, metabolic hydroxylation, oxidative DNA damage, carcinogenesis, etc. [54]. As Zhang et al. [55] reported, the production of ROS is dependent on photosensitizer concentration, as well as, irradiation dose of the light source. In this ex vivo study, the results demonstrate that $2 \times 10^{-4} \mathrm{~g} / \mathrm{L} \mathrm{Zeo/}$ $\mathrm{ZnONPs}$ can generate ROS within polymicrobial biofilms after blue laser irradiation about 1.87 -fold.

To the best of our knowledge, this is the first time to evaluate the remineralization potential of enamel carious lesions. Enamel samples treated with Zeo/ZnONPsbased aPDT exhibited enhanced surface microhardness when compared with samples treated with artificial saliva alone. In this study, like several previous studies, the $\mathrm{NaF}$ varnish was effective for enamel remineralization [5658]. However, aPDT using $2 \times 10^{-4} \mathrm{~g} / \mathrm{L} \mathrm{Zeo} / \mathrm{ZnONPs}$ and the $\mathrm{NaF}$ varnish groups were not statistically different $(P>0.05)$. 


\section{Conclusion}

In summary, the results of this study have proved that Zeo/ZnONPs-based aPDT has emerged a promising potential as an adjuvant therapeutic approach in the fields of anti-biofilms and anti-caries, which are involved with their potent ability to produce ROS. On the other hand, the current results suggest that aPDT using Zeo/ $\mathrm{ZnONPs}$ could have the greatest remineralization efficacy to improve the microhardness of the enamel surface after microbial demineralization.

\section{Materials and methods Statement}

In the current study, all methods and experiments were carried out in accordance with relevant guidelines and regulations.

\section{Synthesis of ZeolZnONPs as the photosensitizer}

Zeo $\backslash \mathrm{ZnONPs}$ was prepared as previously described by Alswata et al. [59] with a slight modification. Briefly, $5 \mathrm{~g}$ of Zeo powder (Sigma-Aldrich, United Kingdom) was dissolved into $100 \mathrm{~mL}$ deionized water to form a solution. $3 \mathrm{~g}$ of $\mathrm{Zn}\left(\mathrm{NO}_{3}\right)_{2} \cdot 4 \mathrm{H}_{2} \mathrm{O}$ (98.5\%; obtained from Merck, Germany) was then added to the suspension. The mixture was stirred under reflux reaction at $80^{\circ} \mathrm{C}$ for $3 \mathrm{~h} .2 \mathrm{M}$ of sodium hydroxide $(\mathrm{NaOH})$ of $99 \%$ (Merck, Germany) was dropped into the solution for precipitation of $\mathrm{ZnO}$ onto the Zeo. The suspension was re-stirred until pH11 was adjusted and the color changed to black. After that, the black product was filtered, washed three times with deionized water, and dried at $80^{\circ} \mathrm{C}$ for $12 \mathrm{~h}$. After drying, the final product was obtained after annealing at $450^{\circ} \mathrm{C}$ for $2 \mathrm{~h}$.

\section{Characterization of Zeo/ZnONPs}

\section{Field emission scanning electron microscopy (FESEM)}

The surface morphology of Zeo/ZnONPs was studied by FESEM (ZEISS, German) under the voltage of $15 \mathrm{kV}$.

\section{Transmission electron microscope (TEM)}

The transmission electron microscope (TEM; Zeiss EM10C) with an accelerating voltage of $80 \mathrm{Kv}$ was used to assess the particle size and size distribution of Zeol ZnONPs.

\section{Dynamic light scattering (DLS) and zeta potential analysis}

The size distribution profiles of nanometer-sized particles in suspension and Zeta potential measurements were carried out using a MALVERN Zetasizer Ver. 6.01 (Malvern Instruments, UK) at approximately $25^{\circ} \mathrm{C}$.

\section{Absorption spectrum}

The absorption spectrum of synthesized Zeo/ZnONPs was carried out by UV-visible spectrophotometer, scanning the absorbance spectra in the range of $350-500 \mathrm{~nm}$ wavelength.

\section{Mapping materials}

Energy dispersive spectroscopy (EDS) mapping was employed to confirm the presence of chemical elements in the structure of $\mathrm{Zeo} / \mathrm{ZnONPs}$.

\section{Hemolytic activity of Zeo/ZnONPs}

The hemolysis experiment was performed to test the biocompatibility of the synthesized NET according to Pourhajibagher et al. study [60]. In summary, after the collection and addition of sodium citrate to $2 \mathrm{~mL}$ of fresh human blood samples obtained from returned unused blood bag in blood bank (Iranian Blood Transfusion Organization), they were washed and centrifuged at $1000 \mathrm{rpm}$ for $10 \mathrm{~min}$ to get the red blood cells (RBCs) as a pellet. The pellet was re-suspended with phosphatebuffered saline (PBS) and treated with an equal volume of synthesized Zeo/ZnONPs at different concentrations $\left(0.5,1\right.$, and $\left.2 \times 10^{-4} \mathrm{~g} / \mathrm{L}\right) .2 \%$ Triton $\mathrm{X}$ and PBS buffer were used as the positive and negative controls, respectively. Following incubation of the samples at $25^{\circ} \mathrm{C}$ for $30 \mathrm{~min}, \mathrm{RBCs}$ were collected as a pellet by centrifugation at $2000 \mathrm{rpm}$ for $3 \mathrm{~min}$. The supernatant was utilized to evaluate the absorbance at $540 \mathrm{~nm}$ using a microplate reader. The percentage of hemolysis was then calculated using the following equation:

$$
\text { Hemolysis }(\%)=\frac{\text { OD test sample }- \text { OD PBS }}{\text { OD Triton } X-\text { OD PBS }} \times 100
$$

\section{Cytotoxicity evaluation of Zeo/ZnONPs \\ Cell culture procedure}

Human gingival fibroblast cells (HuGu; IBRC C10459) obtained from Iranian Biological Resource Center, Tehran, Iran were seeded in a 96-well plate at a plating density of $4 \times 10^{4}$ cells/well. The cells were maintained in $100 \mu \mathrm{L}$ DMEM containing 10\% fetal bovine serum (FBS) solution and antibiotics $(200 \mu \mathrm{L} / \mathrm{mL}$ penicillin $\mathrm{G}, 200 \mu \mathrm{g} /$ $\mathrm{mL}$ streptomycin, and $2 \mu \mathrm{g} / \mathrm{mL}$ fungizone) at $37^{\circ} \mathrm{C}, 5 \%$ $\mathrm{CO}_{2} 95 \%$ air, and $100 \%$ relative humidity. After $24 \mathrm{~h}$, Zeo $\mathrm{ZnONPs}$ at the concentrations of $0.5,1$, and $2 \times 10^{-4} \mathrm{~g} / \mathrm{L}$ were added into the wells and the well-plate was incubated for $24 \mathrm{~h}$ at $37^{\circ} \mathrm{C}, 5 \% \mathrm{CO}_{2}$, and $95 \%$ air with $100 \%$ relative humidity. 


\section{Tetrazolium (MTT)-based cytotoxicity assay}

The cell viability was evaluated using a modified 3-(4, 5-dimethylthiazol-2-yl)-2, 5-diphenyl tetrazolium (MTT) assay. The solutions were removed from each well and $50 \mu \mathrm{L}$ of MTT reagent $(5 \mathrm{mg} / \mathrm{mL})$ was added and the well-plate was incubated for $4 \mathrm{~h}$ at $37^{\circ} \mathrm{C}$ in the $\mathrm{CO}_{2}$ incubator. The MTT solution was then discarded, $100 \mu \mathrm{L}$ of dimethyl sulfoxide (DMSO) was added to dissolved the formed purple crystal formazan, and the absorbance was measured at a wavelength of $570 \mathrm{~nm}$ using a microplate reader. DMEM prepared without the addition of samples were used as the control. Percentage cell viability was determined using the following equation:

$$
\text { Cell viabiliy }(\%)=\frac{\text { Absorbance }(\text { sample })}{\text { Absorbance }(\text { Control })} \times 100
$$

\section{Sulforhodamine B (SRB)-based cytotoxicity assay}

The SRB assay was used to investigate cytotoxicity in cells based on the measurement of cellular protein content [60]. After $24 \mathrm{~h}$ incubation, $\mathrm{HuGu}$ cells were fixed with $10 \%$ (wt/vol) trichloroacetic acid for $30 \mathrm{~min}$. The cells were then washed repeatedly with $1 \%(\mathrm{vol} / \mathrm{vol})$ acetic acid to remove the excess dye. $50 \mu \mathrm{L}$ of SRB solution (0.04\% [wt/vol]; Merck, Germany) was added to each well and the well-plate was incubated at room temperature. After $1 \mathrm{~h}$, the wells were washed four times with $1 \%$ (vol/ vol) acetic acid to remove unbound dye. Finally, $200 \mu \mathrm{L}$ of $10 \mathrm{mM}$ Tris base solution ( $\mathrm{pH} 10.5)$ was used to dissolve the protein-bound dye and OD was determined at a wavelength of $510 \mathrm{~nm}$ using a microplate reader. Percentage cell viability was determined similar to the MTT assay.

\section{Microorganisms and growth conditions}

Standard strains of Streptococcus mutans ATCC 35668, Lactobacillus acidophilus ATCC 314, and Candida albicans ATCC 10231 obtained from Iranian Biological Resource Center, Tehran, Iran were cultured in Brain heart infusion (BHI) broth (Merck, Germany) and incubated at $37^{\circ} \mathrm{C}$ in a shaker incubator at $150 \mathrm{rpm}$ to achieve an optical density (OD) at a wavelength of $600 \mathrm{~nm}$ between $0.08-0.13$, in the same range as equivalent to that of the 0.5 McFarland standard.

\section{Light source}

A blue laser (Laser Diode Stabilizer LDS201, Asha beam profile, Iran) in a continuous beam was used as a light source with an output intensity of $150 \mathrm{~mW} / \mathrm{cm}^{2}, 4.2 \mathrm{~V}$, and $0.34 \mathrm{~A}$ at the wavelength of $405 \pm 10 \mathrm{~nm}$. A photodiode power meter (PMB- 104 power meter, Asha beam profile, Iran) was utilized to measure the output power at the optic tip. All the steps from the operatory protocol were set according to the manufacturer's recommendations.

\section{Enamel slab preparation}

Human premolars without visible cracks, enamel irregularities, and WSLs in the buccal and lingual enamel surfaces which extracted for orthodontic purpose were selected. All teeth experiments have been approved by the Ethics Committee of Tehran University of Medical Sciences (Application No. IR.TUMS.MEDICINE. REC.1400.52106), and the need for informed consent was waived by the ethical committee. All the teeth were disinfected and stored in thymol solution $(0.1 \%)$ at $4{ }^{\circ} \mathrm{C}$ before use.

Enamel slabs (approximately $3 \times 3 \times 1 \mathrm{~mm}$ ) were prepared from mid-labial tooth parts by excision using a water-cooled carborundum disc. For removal of about a $100 \mu \mathrm{m}$ depth of enamel, the flat surface of slabs was then polished with diamond paste (water-based $0.25-\mu \mathrm{m}$ diamond particles). Finally, the prepared enamel slabs were ultrasonically cleaned for $15 \mathrm{~min}$.

\section{Specimen preparation for microbial experiments}

Prepared enamel slabs were etched with the use of $37 \%$ phosphoric acid gel for $30 \mathrm{~s}$, rinsed, and dried for $10 \mathrm{~s}$. A thin layer of a liquid resin primer (Transbond XT primer, 3M Unitek, Orthodontic Products, Monrovia, USA) was brushed on the etched enamel surface and light-cured with the visible light-curing for $20 \mathrm{~s}$. The composite resin was placed onto the titanium orthodontic bracket (Parmis Teb, Isfahan, Iran) and the bracket was bonded on the enamel surface with a consonant force and lightcured for $30 \mathrm{~s}$. The brackets were bonded on the metallic supports made with stainless steel orthodontic wire to suspended the samples for more accumulation of microbial biofilms (Fig. $12 \mathrm{a}-\mathrm{c}$ ). Before the experiments, enamel slabs with bonded brackets and the metallic supports were sterilized using $4.08 \mathrm{kGy}$ of gamma radiation and stored in a humid atmosphere at $4{ }^{\circ} \mathrm{C}$.

\section{Formation of polymicrobial biofilms on the orthodontic brackets}

The orthodontic brackets were placed in the 24-well plates (Ningbo Fuchun, China) with $1.5 \mathrm{~mL}$ BHI broth supplemented with 5\% sucrose, and inoculated with $100 \mu \mathrm{L}$ of each bacterial suspension at the concentration of 0.5 McFarland standard. The orthodontic brackets were incubated at $37^{\circ} \mathrm{C}$ for $72 \mathrm{~h}$ under capnophilic conditions $\left(5 \% \mathrm{CO}_{2}\right)$ for the formation of polymicrobial biofilms [61]. After this time, the brackets were rinsed with PBS (pH 7.4) for removing non-adhered microorganisms. Eventually, the stainless-steel orthodontic wires were detached (Fig. $12 \mathrm{~d}$ ) and the preformed polymicrobial 

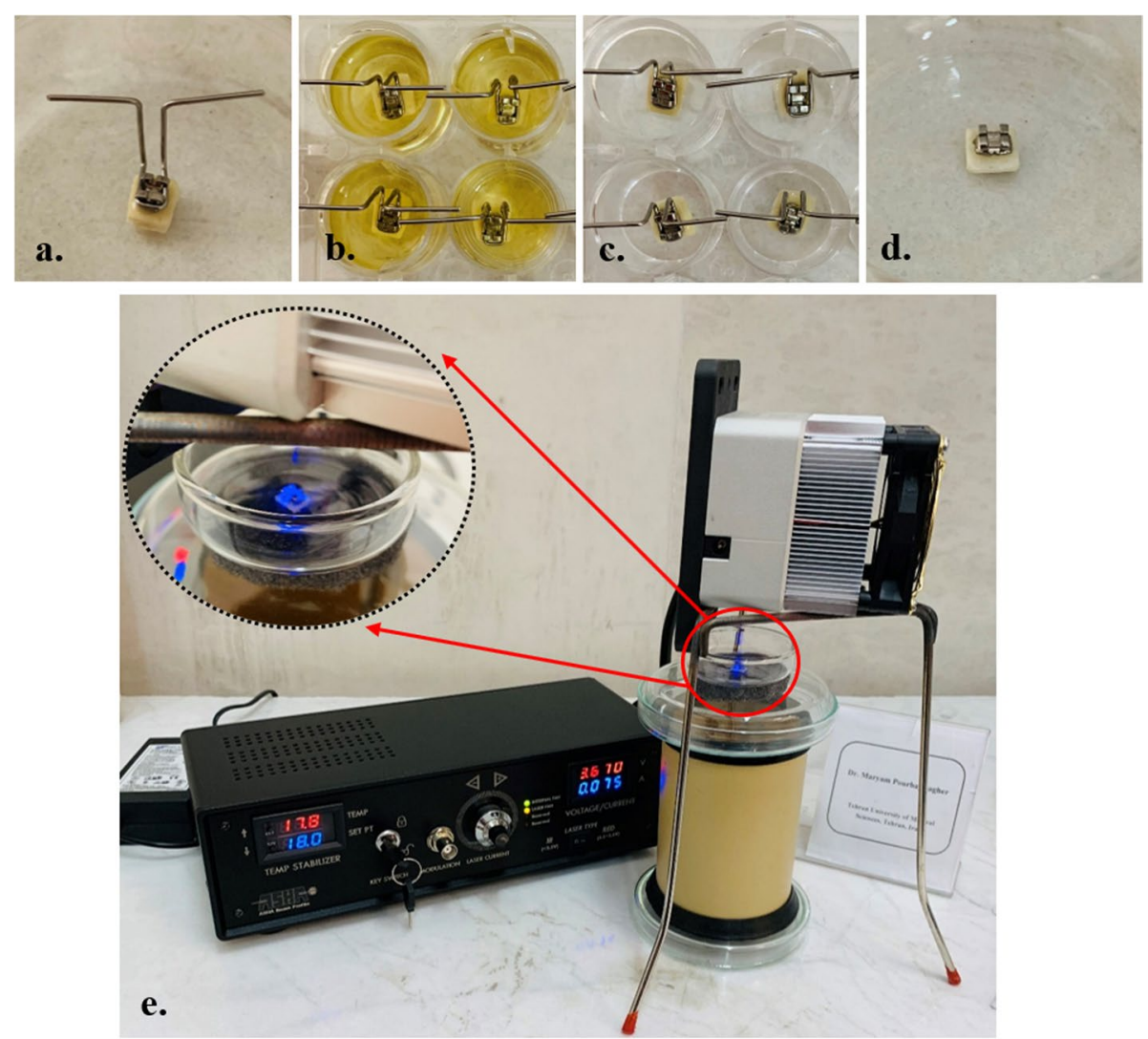

Fig. 12 Treatment process; a Fabrication of enamel slab bonded bracket attached to the stainless-steel orthodontic wires, $\mathbf{b}$ Immersion of the enamel slab bonded bracket in wells of the microplate containing growth medium to formation of microbial biofilms on enamel slab bonded bracket, $\mathbf{c}$ Rinsing of the enamel slab bonded bracket with sterile saline to eliminate the planktonic and weak attached microorganisms, $\mathbf{d}$ Treatment of enamel slab bonded bracket with different concentrations of Zeo/ZnONPs, and e Irradiation of treated enamel slab bonded bracket with a blue laser light

biofilms on the orthodontic bracket were treated according to the study design (Fig. $12 \mathrm{e}$ ).

\section{Experimental design}

The orthodontic brackets were randomly divided into the experimental groups with 10 samples in each group by Random Allocation Software based on the selected type of blocking as follow:
A. Zeo/ZnONPs.
B. Blue laser.
C. aPDT.
D. Positive control: chlorhexidine (CHX).
E. Negative control: Normal saline.

\section{Treatment procedure}

Group A: $100 \mu \mathrm{L}$ of Zeo/ZnONPs at the concentrations of $0.5,1$, and $2 \times 10^{-4} \mathrm{~g} / \mathrm{L}$ was added separately to the orthodontic brackets containing polymicrobial biofilms and the samples were incubated in the dark at room temperature for $5 \mathrm{~min}$.

Group B: Polymicrobial biofilms on the orthodontic brackets were exposed with blue laser irradiation at the wavelength of $405 \pm 10 \mathrm{~nm}$ for $1 \mathrm{~min}$ and output intensity of $150 \mathrm{~mW} / \mathrm{cm}^{2}$. The optical fiber reached up to $2 \mathrm{~cm}$ shorter than working length.

Group C: Polymicrobial biofilms on the orthodontic brackets were treated by $\mathrm{Zeo} / \mathrm{ZnONPs}$ similar to group A and the samples were then exposed with a blue laser similar to group B.

Group D: $100 \mu \mathrm{L}$ of $0.2 \%$ CHX was added to the orthodontic brackets and the samples were incubated at room temperature for $5 \mathrm{~min}$. 
Group E: $100 \mu \mathrm{L}$ of normal saline was added to the orthodontic brackets and the samples were incubated at room temperature for $5 \mathrm{~min}$.

\section{Detection of intracellular ROS production}

The production of ROS by microorganisms involved in polymicrobial biofilms after treatment with different groups was evaluated using 2'-7'-dichlorodihydrofluorescein diacetate (DCFH-DA) (Sigma-Aldrich, United Kingdom) as described by Pourhajibagher et al. [62]. In summary, $100 \mu \mathrm{L}$ of $5 \mu \mathrm{M}$ DCFH-DA was added to the mixture $(100 \mu \mathrm{L})$ of the microorganisms involved in polymicrobial biofilms and shaken at $37^{\circ} \mathrm{C}$ for $10 \mathrm{~min}$. The microbial cells were then centrifuged at $5000 \mathrm{rpm}$ for $15 \mathrm{~min}$ and the pellets were rinsed with PBS. The cleaned microbial cells were treated based on the experimental design section and the fluorescence emission of DCFHDA was measured at $535 \mathrm{~nm}$ using a microplate reader with an excitation wavelength of $488 \mathrm{~nm}$.

\section{Evaluation of anti-biofilm potency}

After treatment of polymicrobial biofilms on the orthodontic brackets according to the experimental design described, each bracket was transferred to a sterile $5 \mathrm{~mL}$ eppendorf containing $2 \mathrm{~mL}$ of PBS and was sonicated at a frequency of $20 \mathrm{kHz}$ and output power of $5 \mathrm{~W}$ for $20 \mathrm{~s}$ to remove the remaining polymicrobial biofilms from the surface of the orthodontic bracket. Then, the serial dilutions were prepared, and $10 \mu \mathrm{L}$ of each dilution was cultured onto BHI agar plates. The plates were incubated at $37^{\circ} \mathrm{C}$ for $24 \mathrm{~h}$ under capnophilic conditions and $\log _{10}$ CFUs/mL was counted based on the previous study [63]. As well as, the anti-biofilm activities of study groups were assessed by SEM.

\section{Evaluation of anti-metabolic activity}

As Coraça-Hubér et al. [64] study, the metabolic activity was assessed using the XTT (2,3-bis [2-methyloxy4-nitro-5-sulfophenyl]-2H-tetrazolium-5-carboxanilide) reduction assay (Roche Applied Science, Indianapolis, IN, US). Following sonication (a frequency of $20 \mathrm{kHz}$ and output power of $5 \mathrm{~W}$ for $20 \mathrm{~s}$ ) of treated orthodontic brackets based on the experimental design section, the microbial suspensions were centrifuged at $2000 \mathrm{rpm}$ for $10 \mathrm{~min}$. The supernatants were removed and microbial cell sediments were dissolved in $150 \mu \mathrm{L}$ of XTT-menadione-PBS solution in 96-well plates and incubated at $37^{\circ} \mathrm{C}$ for $3 \mathrm{~h} .100 \mu \mathrm{L}$ of the solution was then transferred to a new 96-well plate and the OD was measured at $492 \mathrm{~nm}$ using a microplate reader.
Polymicrobial biofilm induced enamel demineralization/ treatment induced remineralization assays

Prepared enamel slabs with a microhardness ranging from 2.52 to 3.09 gigapascals (GPa) were used for multispecies biofilm induced enamel demineralization and treatments induced remineralization assays. For these purposes, enamel slabs were separately transferred aseptically into a sterile 24-well tissue culture plate containing $500 \mu \mathrm{L}$ of sterile artificial saliva and incubated $1 \mathrm{~h}$ at room temperature $\left(22 \pm 2^{\circ} \mathrm{C}\right)$. After that, the saliva was discarded and $1.5 \mathrm{~mL}$ of BHI medium containing $1 \%$ sucrose as the growth medium were added. Plates were incubated in $5 \% \mathrm{CO}_{2}$, for up to 10 days at $37^{\circ} \mathrm{C}$. The growth medium was replaced every $48 \mathrm{~h}$. At the end of the experimental periods, enamel slabs were washed for $10 \mathrm{~s}$ in sterile PBS and transferred to microtubes for enamel demineralization using DIAGNOdent Pen reading and microhardness assays. In this study accepted range of microhardness for enamel demineralization was defined as the previous study (2-3 GPa) [55-57], the demineralized samples would be sorted into distill water for enamel remineralization assays using DIAGNOdent Pen reading and microhardness assays.

\section{Evaluation of the treatment effects on enamel remineralization}

Enamel demineralized samples distributed randomly into 7 groups $(n=10)$ as follows:

A. Remineralization effect of $\mathrm{Zeo} / \mathrm{ZnONPs}$.

B. Remineralization effect of blue laser.

C. Remineralization effect of aPDT at three concentrations of Zeo/ZnONPs $\left(0.5,1\right.$, and $\left.2 \times 10^{-4} \mathrm{~g} / \mathrm{L}\right)$.

D. Remineralization effect of sodium fluoride $(\mathrm{NaF})$ varnish as treatment-control group.

E. Remineralization effect of artificial saliva as the negative control group.

The treatment duration times were 1 month $\left(t_{1}\right)$ and 3 months $\left(t_{2}\right)$. Enamel remineralization was evaluated based on the following assays:

\section{Diagnodent pen reading}

The surface change presented on each experimental enamel slabs after treatment was evaluated at baseline $\left(t_{0}\right)$ and at the end of treatment duration times $\left(t_{1}\right.$ and $t_{2}$ ) using Type B probe of DIAGNOdent Pen 2190 (Kavo, Biberach, Germany) as recommended by the manufacturer guideline. In this assay, $\mathrm{NaF}$ varnish and artificial saliva also stood for the treatment-control group and the negative control group, respectively. The experiment 
was performed in triplicate and the mean value was calculated.

\section{Surface microhardness measurement}

After reading the treated enamel slabs using DIAGNOdent Pen, the slabs were used to measurement of surface microhardness. Enamel surface microhardness (ESM) was assessed using a digital hardness testing machine (FM-700, Future Tech, Tokyo, Japan) as described previously [65]. The mean ESM measurement value of three indentations at intervals of $0.1 \mathrm{~mm}$ which conducted on the surface of each enamel slabs after treatment using a square-based diamond pyramid Vickers's indenter (at a load of $50 \mathrm{~g}$ for $15 \mathrm{~s}$ ) was calculated at baseline $\left(t_{0}\right)$ and the end of treatment duration time.

\section{Data analysis}

All assays were done in triplicate and the data were represented as mean values with standard deviation $( \pm$ $\mathrm{SD})$. The results were statistically evaluated by one-way analysis of variance (ANOVA) and Tukey test. A value of $P<0.05$ was considered statistically significant.

\begin{abstract}
Abbreviations
aPDT: Antimicrobial photodynamic therapy; $\mathrm{BHI}$ : Brain heart infusion; $\mathrm{CHX}$ : Chlorhexidine; NaF: Sodium fluoride; ROS: reactive oxygen species; Zeos: Zeolites; Zeo/ZnONPs: Zeolite-zinc oxide nanoparticles; ZnONPs: Zinc oxide nanoparticles; WSLs: White spot lesions.
\end{abstract}

\section{Acknowledgements}

Not applicable.

\section{Authors' contributions}

M.P. designed the experiments, performed the experiments, analyzed the data, authored or reviewed drafts of the paper, prepared figures and/or tables, and approved the final draft. A.B. conceived and designed the experiments, analyzed the data, authored or reviewed drafts of the paper, and approved the final draft. All authors reviewed the manuscript.

\section{Funding}

This research was supported by Dental Research Center, Dentistry Research Institute, Tehran University of Medical Science and Health Services Grant No. 1400-1-234-52106.

\section{Availability of data and materials}

All data of this manuscript are included in the manuscript. All figures are original images and have been used for the first time in this study Any additional information required will be provided by communicating with the corresponding author via the official mail: abahador@sina.tums.ac.ir.

\section{Declarations}

Ethics approval and consent to participate

The study was approved by the Ethics Committee of Tehran University of Medical Sciences (Application No. IR.TUMS.MEDICINE.REC.1400.52106), and the need for informed consent was waived by the ethical committee.

\section{Consent for publication}

Not applicable.

\section{Competing interests}

The authors declare no conflicts of interest.

\section{Author details}

${ }^{1}$ Dental Research Center, Dentistry Research Institute, Tehran University of Medical Sciences, Tehran, Iran. ${ }^{2}$ Oral Microbiology Laboratory, Department of Microbiology, School of Medicine, Tehran University of Medical Sciences|, Tehran, Iran. ${ }^{3}$ Fellowship in Clinical Laboratory Sciences, BioHealth Lab, Tehran, Iran.

Received: 19 June 2021 Accepted: 6 September 2021

Published online: 07 October 2021

\section{References}

1. Müller LK, Jungbauer $G$, Jungbauer R, Wolf M, Deschner J. Biofilm and orthodontic therapy. Oral Biofilms. 2021;29:201-13.

2. Sifakakis I, Papaioannou W, Papadimitriou A, Kloukos D, Papageorgiou SN, Eliades T. Salivary levels of cariogenic bacterial species during orthodontic treatment with thermoplastic aligners or fixed appliances: a prospective cohort study. Prog Orthod. 2018;19(1):1-9.

3. Ta V, Panchmalb GS, Shenoyc R, Jodallic P, Sonded L, Kundapure N. Changes in the oral environment after placement of fixed orthodontic appliance for the treatment of malocclusion-a descriptive longitudinal study. Oral Health Prev Dent. 2017;15:453-9.

4. Fernandez-Ferrer L, Vicente-Ruiz M, Garcia-Sanz V, Montiel-Company $J M$, Paredes-Gallardo V, Almerich-Silla JM, et al. Enamel remineralization therapies for treating postorthodontic white-spot lesions: a systematic review. J Am Dent Assoc. 2018;149(9):778-86.

5. Govindaraj A, Dinesh SP. Effect of Chlorhexidine varnish and fluoride varnish on white spot lesions in orthodontic patients-a systematic review. Open Dent J. 2021;15(1):1-6.

6. Papaioannou W, Panagopoulos A, Koletsi-Kounari H, Kontou E, Makou M. Adhesion of Porphyromonas gingivalis and biofilm formation on different types of orthodontic brackets. Int J Dent. 2012;2012:1-6.

7. Santos VR, Valdez RM, Danelon M, Souza JA, Caiaffa KS, Delbem AC, et al. Effect of S. mutans combinations with bifidobacteria/lactobacilli on biofilm and enamel demineralization. Braz Oral Res. 2021;35:1-5.

8. Grzegocka K, Krzyściak P, Hille-Padalis A, Loster JE, Talaga-Ćwiertnia K, Loster BW. Candida prevalence and oral hygiene due to orthodontic therapy with conventional brackets. BMC Oral Health. 2020;20(1):1-9.

9. Fleming PS, Johal A. Self-ligating brackets in orthodontics: a systematic review. Angle Orthod. 2010;80(3):575-84.

10. Dehbi H, Azaroual MF, Zaoui F, Halimi A, Benyahia H. Therapeutic efficacy of self-ligating brackets: a systematic review. Int Orthod. 2017;15(3):297-311.

11. Kellesarian SV, Qayyum F, De Freitas PC, Akram Z, Javed F. Is antimicrobial photodynamic therapy a useful therapeutic protocol for oral decontamination? A systematic review and meta-analysis. Photodiagn Photodyn Ther 2017:20:55-61.

12. Fraga RS, Antunes LA, Fontes KB, Küchler EC, lorio NL, Antunes LS. Is antimicrobial photodynamic therapy effective for microbial load reduction in Peri-implantitis treatment? A systematic review and Meta-analysis. Photochem Photobiol. 2018:94(4):752-9.

13. Panhóca VH, Esteban Florez FL, Corrêa TQ, Paolillo FR, de Souza CW, Bagnato VS. Oral decontamination of orthodontic patients using photodynamic therapy mediated by blue-light irradiation and curcumin associated with sodium dodecyl sulfate. Photomed Laser Surg. 2016;34(9):411-7.

14. Pourhajibagher M, Bahador A. Is antimicrobial agents can considered as effective weapons against endodontic infections by enterococcus faecalis? Der Pharma Chem. 2015;7:196-200

15. Pourhajibagher M, Kazemian H, Chiniforush N, Hosseini N, Pourakbari $B$, Azizollahi A, et al. Exploring different photosensitizers to optimize elimination of planktonic and biofilm forms of enterococcus faecalis from infected root canal during antimicrobial photodynamic therapy. Photodiagn Photodyn Ther. 2018:24:206-11.

16. Konopka KR, Goslinski TO. Photodynamic therapy in dentistry. J Dent Res. 2007:86(8):694-707. 
17. Pourhajibagher M, Vaziri AS, Takzaree N, Ghorbanzadeh R. Physicomechanical and antimicrobial properties of an orthodontic adhesive containing cationic curcumin doped zinc oxide nanoparticles subjected to photodynamic therapy. Photodiagn Photodyn Ther. 2019;25:239-46.

18. Ancona A, Dumontel B, Garino N, Demarco B, Chatzitheodoridou D, Fazzini W, et al. Lipid-coated zinc oxide nanoparticles as innovative ROS-generators for photodynamic therapy in cancer cells. Nanomaterials. 2018;8(3):143.

19. Youssef Z, Vanderesse R, Colombeau L, Baros F, Roques-Carmes T, Frochot $C$, et al. The application of titanium dioxide, zinc oxide, fullerene, and graphene nanoparticles in photodynamic therapy. Cancer Nanotechnol. 2017;8(1):1-62.

20. Jiang J, Pi J, Cai J. The advancing of zinc oxide nanoparticles for biomedical applications. Bioinorg Chem Appl. 2018;2018:1-18.

21. Kamari HM, Al-Hada NM, Saion E, Shaari AH, Talib ZA, Flaifel MH, et al. Calcined solution-based PVP influence on $\mathrm{ZnO}$ semiconductor nanoparticle properties. Crystals. 2017;7(2):1-14.

22. Al-Hada NM, Saion E, Shaari AH, Kamarudin MA, Gene SA. The influence of calcination temperature on the formation of zinc oxide nanoparticles by thermal-treatment. Appl Mech Mater. 2014:446:181-4.

23. Azam A, Ahmed AS, Oves M, Khan MS, Habib SS, Memic A. Antimicrobial activity of metal oxide nanoparticles against gram-positive and gram-negative bacteria: a comparative study. Int J Nanomedicine. 2012;7:6003-9

24. Sani HA, Ahmad MB, Saleh TA. Synthesis of zinc oxide/talc nanocomposite for enhanced lead adsorption from aqueous solutions. RSC Adv. 2016;6(110):108819-27.

25. Alswat AA, Ahmad MB, Saleh TA. Preparation and characterization of zeolite \zinc oxide-copper oxide nanocomposite: antibacterial activities. Colloids Interface Sci Commun. 2017;16:19-24.

26. Zotti F, Dalessandri D, Salgarello S, Piancino M, Bonetti S, Visconti L, et al. Usefulness of an app in improving oral hygiene compliance in adolescent orthodontic patients. Angle Orthod. 2016;86(1):101-7.

27. Marsh PD. Dental plaque as a biofilm and a microbial communityimplications for health and disease. BMC Oral health. 2006:6(1):1-7.

28. Sbordone L, Bortolaia C. Oral microbial biofilms and plaque-related diseases: microbial communities and their role in the shift from oral health to disease. Clin Oral Investig. 2003;7(4):181-8.

29. Hirose M, Yoshida Y, Horii K, Hasegawa Y, Shibuya Y. Efficacy of antimicrobial photodynamic therapy with rose Bengal and blue light against cariogenic bacteria. Arch Oral Biol. 2021;122:105024.

30. Méndez DA, Gutierrez E, Dionísio EJ, Oliveira TM, Buzalaf MA, Rios $D$, et al. Effect of methylene blue-mediated antimicrobial photodynamic therapy on dentin caries microcosms. Lasers Med Sci. 2018;33(3):479-87.

31. Cieplik F, Buchalla W, Hellwig E, Al-Ahmad A, Hiller KA, Maisch T, et al. Antimicrobial photodynamic therapy as an adjunct for treatment of deep carious lesions - a systematic review. Photodiagn Photodyn Ther. 2017:18:54-62

32. Mylona V, Anagnostaki E, Parker S, Cronshaw M, Lynch E, Grootveld M. Laser-assisted aPDT protocols in randomized controlled clinical trials in dentistry: a systematic review. Dent J. 2020;8(3):107-12.

33. Reis AC, Regis WF, Rodrigues LK. Scientific evidence in antimicrobial photodynamic therapy: an alternative approach for reducing cariogenic bacteria. Photodiagn Photodyn Ther. 2019;26:179-89.

34. Santin GC, Oliveira DS, Galo R, Borsatto MC, Corona SA. Antimicrobial photodynamic therapy and dental plaque: a systematic review of the literature. Sci World J. 2014;2014:1-8.

35. Alves LV, Curylofo-Zotti FA, Borsatto MC, de Souza Salvador SL, Valério RA, Souza-Gabriel AE. Influence of antimicrobial photodynamic therapy in carious lesion. Randomized split-mouth clinical trial in primary molars. Photodiagn Photodyn Ther. 2019;26:124-30.

36. Simionato MR, Ramalho KM, Imparato JC, Pinheiro SL, Luz MA. Clinical use of photodynamic antimicrobial chemotherapy for the treatment of deep carious lesions. J Biomed Opt. 2011;16(8):088003-7.

37. Méndez DA, Gutierres E, Dionisio EJ, Buzalaf MA, Oliveira RC, Machado MA, et al. Curcumin-mediated antimicrobial photodynamic therapy reduces the viability and vitality of infected dentin caries microcosms. Photodiagn Photodyn Ther. 2018;24:102-8.
38. Alqerban A. Effectiveness of riboflavin and rose Bengal photosensitizer modified adhesive resin for orthodontic bonding. Pharmaceuticals. 2021;14(1):1-11.

39. Panhóca VH, Geralde MC, Corrêa TQ, Carvalho MT, Souza CW, Bagnato VS. Enhancement of the photodynamic therapy effect on Streptococcus mutans biofilm. J Phys Sci. 2014;4(2):1-8.

40. Ismail AF, Ali MM, Ismail LF. Photodynamic therapy mediated antiproliferative activity of some metal-doped ZnO nanoparticles in human liver adenocarcinoma HepG2 cells under UV irradiation. J Photochem Photobiol B. 2014;138:99-108.

41. Fakhar-e-Alam M, Rahim S, Atif M, Aziz MH, Malick MI, Zaidi SS, et al. $\mathrm{ZnO}$ nanoparticles as drug delivery agent for photodynamic therapy. Laser Phys Lett. 2013;11(2):1-7.

42. Ancona A, Dumontel B, Garino N, Demarco B, Chatzitheodoridou D, Fazzini W, et al. Lipid-coated zinc oxide nanoparticles as innovative ROS-generators for photodynamic therapy in cancer cells. Nanomaterials. 2018;8(3):1-15.

43. Gu B, Pliss A, Kuzmin AN, Baev A, Ohulchanskyy TY, Damasco JA, et al. In-situ second harmonic generation by cancer cell targeting $\mathrm{ZnO}$ nanocrystals to effect photodynamic action in subcellular space. Biomaterials. 2016;104:78-86

44. Hanim SA, Malek NA, Ibrahim Z. Amine-functionalized, silver-exchanged zeolite NaY: preparation, characterization and antibacterial activity. Appl Surf Sci. 2016:360:121-30

45. Cerri G, De'Gennaro M, Bonferoni MC, Caramella C. Zeolites in biomedical application: Zn-exchanged clinoptilolite-rich rock as active carrier for antibiotics in topical therapy. Appl Clay Sci. 2004;27:141-50.

46. Đolić MB, Rajaković-Ognjanović VN, Štrbac SB, Dimitrijević SI, Mitrić $\mathrm{MN}$, Onjia $\mathrm{AE}$, et al. Natural sorbents modified by divalent $\mathrm{Cu}(2+)$ - and $\mathrm{Zn}(2+)$-ions and their corresponding antimicrobial activity. New Biotechnol. 2017:39:150-9.

47. Yao G, Lei J, Zhang W, Yu C, Sun Z, Zheng S, et al. Antimicrobial activity of X zeolite exchanged with $\mathrm{Cu} 2+$ and $\mathrm{Zn} 2+$ on Escherichia coli and Staphylococcus aureus. Environ Sci Pollut Res. 2019;26(3):2782-93.

48. Wang SW, Lee CH, Lin MS, Chi CW, Chen YJ, Wang GS, et al. ZnO nanoparticles induced caspase-dependent apoptosis in gingival squamous cell carcinoma through mitochondrial dysfunction and p7056K signaling pathway. Int J Mol Sci. 2020;21:1-15.

49. Şeker Ş, Elcin $A E$, YumakT, Sınağ A, Elcin YM. In vitro cytotoxicity of hydrothermally synthesized $\mathrm{ZnO}$ nanoparticles on human periodontal ligament fibroblast and mouse dermal fibroblast cells. Toxicol in Vitro. 2014;28:1349-58.

50. Vergara-Llanos D, Koning T, Pavicic MF, Bello-Toledo H, Díaz-Gómez A, Jaramillo A, et al. Antibacterial and cytotoxic evaluation of copper and zinc oxide nanoparticles as a potential disinfectant material of connections in implant provisional abutments: an in-vitro study. Arch Oral Biol. 2021:122:1-8.

51. Vajrabhaya LO, Korsuwannawong S. Cytotoxicity evaluation of a Thai herb using tetrazolium (MTT) and sulforhodamine B (SRB) assays. Anal Sci Technol. 2018;9(1):1-6.

52. Babu EP, Subastri A, Suyavaran A, Premkumar K, Sujatha V, Aristatile B, et al. Size dependent uptake and hemolytic effect of zinc oxide nanoparticles on erythrocytes and biomedical potential of ZnO-ferulic acid conjugates. Sci Rep. 2017;7(1):1-12.

53. Ulyanova NY, Kurylenko LN, Shamova OV, Orlov DS, Golubeva OY. Hemolitic activity and sorption ability of Beta zeolite nanoparticles. Phys Chem Glasses. 2020:46:155-61.

54. Garcia-Diaz M, Huang YY, Hamblin MR. Use of fluorescent probes for ROS to tease apart type I and type II photochemical pathways in photodynamic therapy. Methods. 2016;109:158-66.

55. Zhang Y, Chen W, Wang S, Liu Y, Pope C. Phototoxicity of zinc oxide nanoparticle conjugates in human ovarian cancer $\mathrm{NIH}$ : OVCAR-3 cells. J Biomed Nanotechnol. 2008;4:432-8.

56. Nozari A, Ajami S, Rafiei A, Niazi E. Impact of nano hydroxyapatite, nano silver fluoride and sodium fluoride varnish on primary teeth enamel remineralization: an in vitro study. J Clin Diagn Res. 2017;11(9):97-103.

57. Cardoso CA, Cassiano LP, Costa EN, Souza-E-Silva CM, Magalhães AC, Grizzo LT, et al. Effect of xylitol varnishes on remineralization of artificial enamel caries lesions in situ. J Dent. 2016:50:74-8. 
58. Restrepo M, Jeremias F, Santos-Pinto L, Cordeiro RC, Zuanon AC. Effect of fluoride varnish on enamel remineralization in anterior teeth with molar incisor hypomineralization. J Clin Pediatr Dent. 2016;40(3):207-10.

59. Alswata AA, Bin Ahmad M, Al-Hada NM, Kamari HM, Bin Hussein MZ, Ibrahim NA. Preparation of zeolite/zinc oxide nanocomposites for toxic metals removal from water. Results Phys. 2017;7:723-31.

60. Pourhajibagher M, Partoazar A, Alaeddini M, Etemad-Moghadam S, Bahador A. Photodisinfection effects of silver sulfadiazine nanoliposomes doped-curcumin on Acinetobacter baumannii: a mouse model. Nanomedicine. 2020;15(05):437-52.

61. Tupinambá RA, Claro CA, Pereira CA, Nobrega CJ, Claro AP. Bacterial adhesion on conventional and self-ligating metallic brackets after surface treatment with plasma-polymerized hexamethyldisiloxane. Dental Press J Orthod. 2017;22(4):77-85.

62. Pourhajibagher M, Rahimi esboei B, Hodjat M, Bahador A Sonodynamic excitation of nanomicelle curcumin for eradication of Streptococcus mutans under sonodynamic antimicrobial chemotherapy: Enhanced anti-caries activity of nanomicelle curcumin. Photodiagnosis Photodyn Ther 2020;30:101780.
63. Pourhajibagher M, Rokn AR, Barikani HR, Bahador A. Photo-sonodynamic antimicrobial chemotherapy via chitosan nanoparticles-indocyanine green against polymicrobial periopathogenic biofilms: ex vivo study on dental implants. Photodiagn Photodyn Ther. 2020;31:101834.

64. Coraça-Hubér DC, Fille M, Hausdorfer J, Pfaller K, Nogler M. Evaluation of MBEC $^{\mathrm{TM}}$-HTP biofilm model for studies of implant associated infections. J Orthop Res. 2012;30(7):1176-80.

65. Prabhakar AR, Taur S, Hadakar S, Sugandhan S. Comparison of antibacterial efficacy of calcium hydroxide paste, $2 \%$ chlorhexidine gel and turmeric extract as an intracanal medicament and their effect on microhardness of root dentin: an in vitro study. Int J Clin Pediatr Dent. 2013;6(3):171.

\section{Publisher's Note}

Springer Nature remains neutral with regard to jurisdictional claims in published maps and institutional affiliations.
Ready to submit your research? Choose BMC and benefit from:

- fast, convenient online submission

- thorough peer review by experienced researchers in your field

- rapid publication on acceptance

- support for research data, including large and complex data types

- gold Open Access which fosters wider collaboration and increased citations

- maximum visibility for your research: over $100 \mathrm{M}$ website views per year

At BMC, research is always in progress.

Learn more biomedcentral.com/submissions 